Portland State University

PDXScholar

1975

\title{
A Study of Student Clinicians' Behaviors in Response to Feedback from the Analysis of Behaviors of the Clinician (ABC) System
}

Susan Kay Clare

Portland State University

Follow this and additional works at: https://pdxscholar.library.pdx.edu/open_access_etds

Part of the Speech and Hearing Science Commons, and the Speech Pathology and Audiology Commons

Let us know how access to this document benefits you.

\section{Recommended Citation}

Clare, Susan Kay, "A Study of Student Clinicians' Behaviors in Response to Feedback from the Analysis of Behaviors of the Clinician (ABC) System" (1975). Dissertations and Theses. Paper 2260.

https://doi.org/10.15760/etd.2257

This Thesis is brought to you for free and open access. It has been accepted for inclusion in Dissertations and Theses by an authorized administrator of PDXScholar. Please contact us if we can make this document more accessible: pdxscholar@pdx.edu. 
AN ABSTRACT OF MHE THESIS OF Susan Kay Clare for the Master of Science in Speech Communication, Emphasis Speech Pathology and Audiology presented May 16, 1975.

Titles A Study of Student Clinicians' Behaviors in Response to Feedback from the Analysis of Behaviors of the Clinician ( $A B C$ ) System

APPROVED BY MEMBERS OF THE THESIS COMMITTEE \&

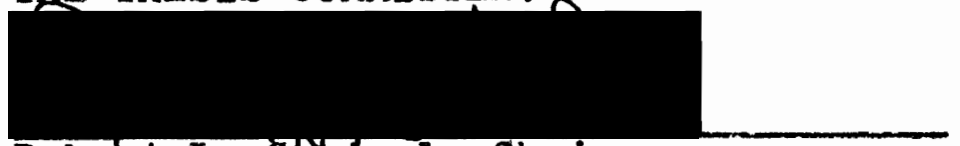

Robert I. Casteel, Chairman

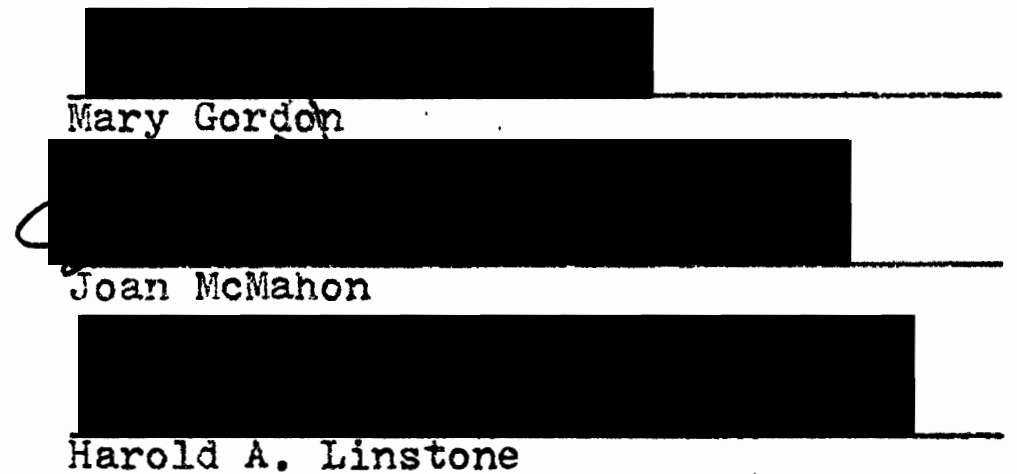

The major gozl of supervisors in the area of Speech Pathology is to help student clinicians improve efficiency and effectiveness in attaining a therapeutic goas. This study was designed to provide systematic feedback of recorded data to student clinicians to determine the effect of a particular supervisory instrument on the future performance of inexperienced clinicians. The subjects for this study were six beginning student clinicians in speech 
Pathology at Portland State University, two of which were randomly selected to represent the control group.

All of the clinicians were observed for a randomly selected consecutive five-minute period from each of six management sessions. During these observations a content analysis was made of the interactions between the clinicians and their clients. The Analysis of Behavior of the Clinician ( $A B C$ ) System, developed by Schubert and Miner (1971) was used to record interactions on a three-second interval schedule. The observation sessions for the control group coincided in time with the experimental group's observation sessions, though no feedback was given to the control clinicians and they were unaware that tracking was done.

All of the observations were recorded one week apart and designated as Data Sessions 1,2,3,4,5 and 6. Pre-experimental equivalence of the control and experimental groups was measured by comparing the behaviors observed during the first two Data Sessions.

The experimental group was involved in three Treatment Sessions in addition to the traditional supervision which both groups received. Treatment I followed Data Session 3 and consisted of presenting the experimental clinicians with a composite graph of their interaction profiles that was derived from the $A B C$ System information gathered from the first three Data Sessions and a verbal 
definition of each of the System's twelve behavioral categories. No further instruction or advice was given to the clinicians such as suggesting areas of change or criteria for evaluation. In addition, the supervisor of the clinic was not aware of which clinicians composed the experimental group.

A graph compiled from the behaviors tracked from Data Session 4 one week later was presented to the experimental clinicians immediately following the session as the Treatment II phase of the experiment. The procedure was repeated for Treatment III, using interactions recorded from Data Session 5. One additional session was observed and tracked a week later, Data Session 6, but the information was not shared with the clinicians. This session was tracked in order to measure the results of the last intervention phase of the study.

The results indicated that systematic feedback to student clinicians using the $A B C$ system positively affected change in their behavior beyond maturation and routine supervision. The experimental clinicians differed from their own baseline performance and the control clinicians' performance during the last two data sessions in four parameters. They used significantly more positive reinforcement and significantly less reinforcement of incorrect responses, less irrelevant behavior and less punishment. The clients of the experimental group responded with 
significantly more correct responses and significantly

less incorrect responses than the clients of the control

group during the last two sessions of the study. 
A STUDY OF STUDENT CIINICIANS' BEHAVIORS IN RESPONSE

TO FEEDBACK FROM THE ANAIYSIS OF BEHAVIORS

OF THE CIINICIAN (ABC) SYSTEM

\author{
by \\ SUSAN KAY CLARE
}

A thesis submitted in partial fulfillment of the requirements for the degree of

MASTER OF SCIENCE IN SPEECH COMMUNICATION,

EIMPHASIS SPEECH PATHOIOGY AND AUDIOIOGY

Portland State University

1975 
TO THE OFFICE OF GRADUATE STUDIES AND RESEARCH:

The members of the Committee approve the thesis of Susan Kay Clare presented May 16, 1975.
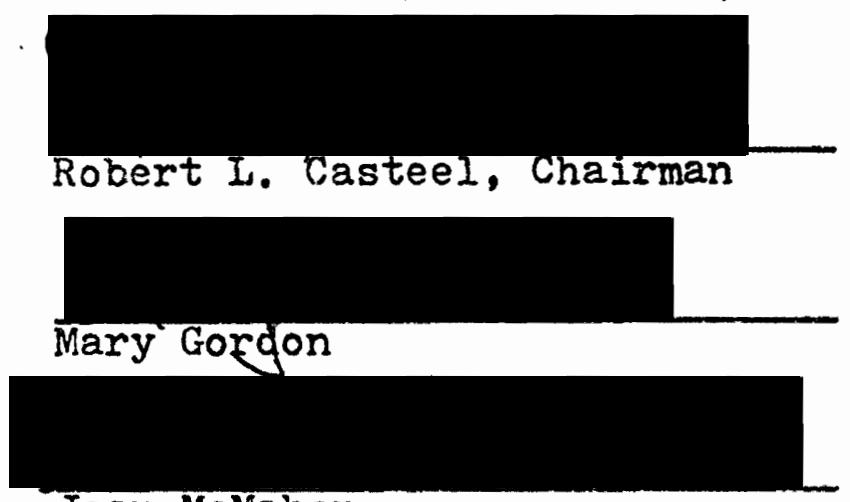

Joan McMahon

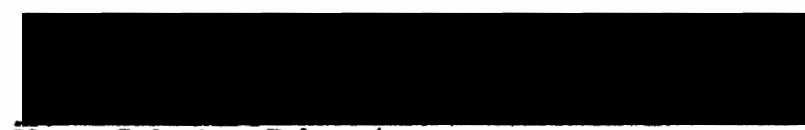

Harold A. Iinstone

APPROVED:

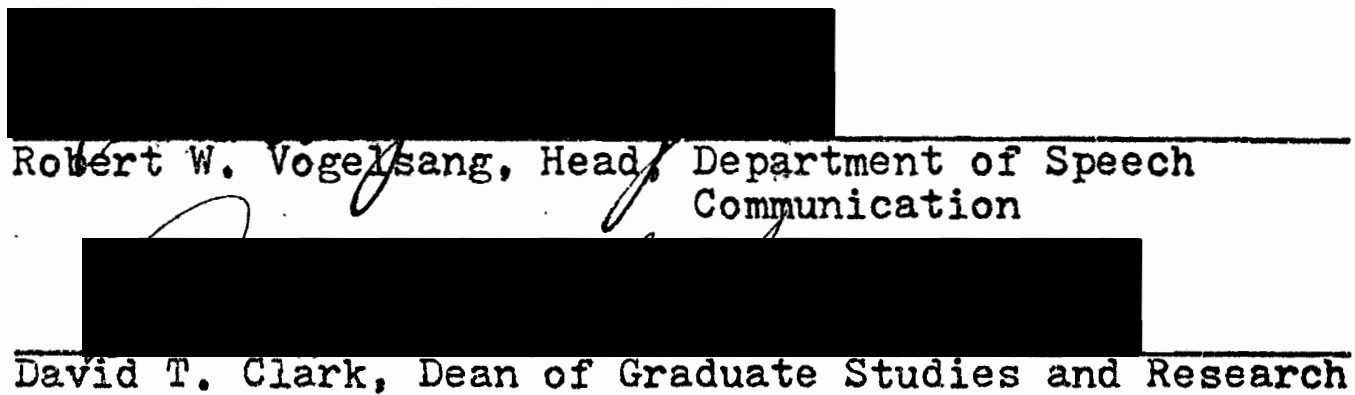

May 16, 1975 


\section{ACKNOWLEDGEMENTS}

The author owes many personal debts of gratitude for assistance. Many of the ideas presented in this thesis are not solely the author's; they reflect an association with the excellent program at Portland State University, the experiences of many student colleagues with whom the author has had the pleasure of interacting, and the capable reactions of my committee members, particularly Dr. Robert Casteel, Joan McMahon and Mary Gordon. Dr. Adah Miner gave unselfishly her time and assistance in the design of the project and directed me to much appreciated reference material. Dr. Jack Hegrenes, who assisted with the statistics, was ever helpful and understanding.

My gratitude to my mother for her faith and encouragement. And last but not least, my thanks to my husband, Larry, to whom I now return if he will have me back and to my children, Kathy and Patrick, who I fondly hope still remember me. 
TABLE OF CONTENTS

PAGE

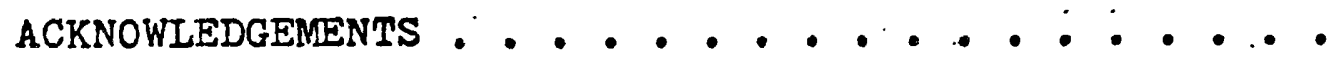

LIST OF TABLES

vi

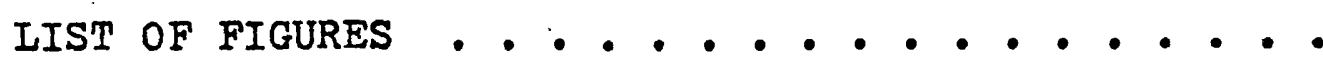

vii

CHAPTER

I INTRODUCTION AND STATEMENT OF PURPOSE • • -

I Introduction ..............

II Statement of Purpose . . . . . . 3

II REVIEW OF THE IITERATURE . • . •. • • . . 5

I The Role of a Supervisor.. ..... 5

II The Need for Quality Supervision . . . 6

III The Importance of Systematic Feedback.

IV Interaction Analysis Systems for

Speech Clinicians. . . . . . .

II NETHODS AND PROCEDURES • • • • • • • •

I Subjects . . '. . . . . . . . .

Control Group. .. . . . . . .

Instrumentation. . . . . . . .

Reliability. •. . . . • . . . •

II Procedure. . . . . . . . . . .

Treatment Procedures . . . . . .

II Data Analysis. . . . . . . . . 
CHAPTER

PAGE

IV RESULTS AND DISCUSSION •. • . . • • •

I Results. . . . . . . . . .

Comparison of Experimental and

Control Groups for Period I. . . . .

25

Comparison of Experimental and

Control Groups for Period II . . . .

28

Comparison of Period I and Period II

for the Experimental Group . . . . .

31

Comparison of Period I and Period II for the Control Group . . . . . .

33

Comparison of Interaction Ratios for Periods I and II . . . . . . . .

II Discussion ......... . 39

Significant Differences. . . . . 39

Additional Findings. . . . . . . 41

Comparison with Previous Research. . . 44

V SUMMARY AND IMPLICATIONS . . . . . . 49

I summary. . . . . . . . . 49

II Implications . . . . . . . . 51

Implications for Clinical Training . . $\quad 51$

Implications for Clinical Research.. . 53

REFERENCES . . . . . . . . . . . 55

APPENDICIES ................... 58

A Raw Data Collection Sheet. . ...... 58

B. Quick Analysis Form. . . . . . . . 59

C Excerpt from Training Manual For An InterAction Analysis System For Identifying the Behavior of Speech And Language Clinicians, Miner, 1971. . . . . . . . .... 


\section{IIST OF TABIES}

TABIE

PAGE

I Mean Percentage of Use of Each

Category For Six Sessions . . . . . . . .

II Comparison of Control and Experimental.

Groups For Period I (Data Sessions 1 and 2).

III Comparison of Control and Experimental

Groups For Period II (Data Sessions 5 and 6).

IV Comparison of Period I and Period II

For The Experimental Group.: . . . . .

$V$ Comparison of Period I and Period II

For the Control Group . . ... . . . . .

VI Comparison of Interaction Ratios For

Period I and Period II For The Experimental

Group . . . . . . . . . . ... . . . .

VII Comparison of Interaction Ratios For Period I And Period II For The Control Group .....

VIII Mean Percentage of Occurrance of a Particular Behavior When Comparing Class I and Class II CIinicians of the Schubert Study (1971) with Experimental and Control Clinicians for Data Sessions 4, 5, and 6 . . . . . . . . 


\section{IIST OF FIGURES}

FIGURE

PAGE

I Boone and Prescott Ten Category System...

11

II Analysis of Behavior of Clinicians (ABC) System ............. 14

III Schematic Illustration of Procedure. . . . 


\section{CHAPTER I}

\section{INTRODUCTION AND STATEMENT OF PURPOSE}

\section{INTRODUCTION}

The major goal of supervisors in the area of speech. pathology is to help student clinicians improve efficiency and effectiveness in attaining a therapeutic goal. The optimal course of training for the student in order to reach this goal is still undefined and thus varies greatly. within and between training institutions.

Often the student clinician, even after considerable successful practicum, Iinds himself wishing for workable rules. He is equipped with a limited armament of clinical skills that cannot be applied univergally to all cllents in all situations. The conflict between limited experience and the practical problem of gaining more experience and supervision, results in a kind of idiosyncratic, trial-and-error learning process. This process continues since clinical practicum, no matter how extensive, can never cover the full range of possible problens, and the gaps left in the student clinician's training eventually force $\mathrm{him}$ to rely on clinical intuition and judgement. These latter commodities might serve well for guidance of an experienced clinician, but their early validity in the case of the 
student are questianable. It is the presence of untested sets of alternatives and hypotheses that make it virtualiy imposaible for the student clinician to isolate the variables that will make analysis of the therapeutic process meaningful to him.

Hopefully, systematic observations of the events associated with clinical training could provide the accumulation of facts that would promote an understanding of the events observed. Although it may not be possible to define accurately and analyze completely all the complex variables pertinent to the training process, it is possible to make observations of the results of the management process and the common factors that contribute to it. Several authors (Dietrich, 1966, Brooks and Hannah, 1966; Anderson, 1973) have identified a need for quantitative tools for use in supervision; however, attempts at developing specific instruments have been recent and their effects largely unresearched. It would seem a profitable endeavor, therefore, to investigate change in student clinicians ' management behaviors in response to a recently developed supervisory instrument.

If the therapeutic process is viewed as the observable behavior which occurs between the clinician and the client within a specified time for the purpose of modifying the client's behavior, the problem becomes more empirical. The most appropriate means for studying the observable 
events occurring between two people would seem to be an interaction analysis of behavioral events. Using this paradigm, selected behavioral interactions are noted, identifying behaviors under examination. From an analysis of these patterns of interactions, the management techniques of the clinician as well as the client's behavior can be studied.

It would seem logical to assume that supervisors and student clinicians would profit by systematically examining what transpired during the clinical sessions. Hypotheses for optimum use of management time could be more empirically tested and their results more clearly demonstrated to the student clinician. The subjective element of supervision could be lessened as well as the unproductive emotional reactions of student clinicians. Equally as important would be the student clinician's becoming equipped with the skill of determining exactly what transpired during the treatment process, thus reducing his subjective appraisal of the effectiveness of his clinical strategies.

\section{STATEMENT OF PURPOSE}

This study was designed to provide systematic feedback of recorded data to student clinicians to determine the effect of a particular supervisory instrument on the futuxe performance of inexperienced clinicians. A time- 
sampling interaction analysis (The Analysis of Behavior of the Clinician System, Schubert and Miner, 1971) provided behaviorally stated information which was shared with the experimental group of clinicians to enable them to view how they invested their clinical time.

The null hypothesis was that there would be no sigrificant changes in the use of any of the behaviors studied after the experimental group was exposed to the data. 
CHAPTER II

REVIEW OF THE LITERATURE

I THE ROLE OF A SUPERVISOR

In emphasizing the importance of the role of a student clinician supervisor, Halfond (1964) described the supervisor as "someone who helps the clinician integrate theory and practice so that skill in the area of clinical processes will be maximized." The consequences of this facet of a student clinician's training, as Van Riper (1965) pointed out, will affect the outcome of treatment for thousands of clients throughout the clinician's professional career.

The supervisor takes a role with the student clinician much like the role of the clinician-client relationship which Rogers (1961) described as "one in which at least one of the parties has the intent of promoting growth, development, maturity, improved functioning and improved coping with Iife of the other." The way supervisors fulPill this intention is explored in the literature.

In 1964 a conference was held in Boulder. Colorado, by the American Speech and Hearing Association entitied, "Seminar on Guidelines for Supervision of Clinical Practicum in Programs of Training for Speech Pathologist and 
Audiologists." Subsequently, a publication was distributed to all training institutions. The first page of this document stated

Clinical practicum is a critical part of the total preparation . - . And he must practice under careful supervision until there is no doubt that he can work independently.

The conference raised the following questions: what is careful supervision; how should supervisors go about shaping the behaviors of student clinicians; what are the observable behaviors that constitute clinical competency?

II THE NEED FOR QUAIITY SUPERVISION

Black (1961) surveyed, nationally, supervisors at the state and local levels. Of the 141 responding supervisors, she found, "There is a wide variation of opinion concerning the importance of various duties of supervisors." She felt objective criteria concerning procedures followed in supervising remedial work is lacking.

Rees (1967) found in a survey of college supervisors. master clinicians, and former students, a significant dissatisfaction. with supervision and procedures used for evaluation of practicum by college personnel.

In order to determine criteria for good supervision. Stace and Drexler (1969) surveyed private hearing and speech centers. Suggestions for improvement by respondents were vague, but appeared to be centered around a concept which Stace and Drexler described as "experience-based 
learning activities."

Van Riper (1965) discussed the supervisor's use of positive feedback as an indication of competency to student clinicians. He asserted that this helps motivate the clinician and better enables him to accept constructive criticism.

In $a$ discussion of an induction $100 \mathrm{p}$ and hearing-aid system for use in supervision, Brooks and Hannah (1966) pointed out, "The dynamics of the student-supervisor relationship may require delicate management at times if personality conflicts are not to interfere with the success of the supervision and growth of the student." Yet, regardless of the method employed, it would seem the supervisor should discuss his thoughts regarding the treatment session with the clinician in order that the student might learn from the supervisor's management experience. As Darley (1969) stateds

The clinical supervisor should be more than nominal. The supervisor cannot find out what the clinician is doing by reading logs written by him last week... It is a necessity that we improve clinical experience. And the influence of clinical supervision must take a scientific attack on real life questions.

\section{THE IMPORTANCE OF SYSTEMATIC FEEDBACK}

The communication between the clinician and the supervisor is what Barnlund (1968) described as a "Purposive message." Three elements are essential to the feedback 
process (purposive message) for the purpose of improving clinical skills: 1) Information about the characteristics of the clinician's present level of performance, 2) $A$ recognition of the discrepancy between the cliniclan's present behaviors and the ideal or intended level of performance, and 3) Suggestions for modification of future behaviors to reduce the discrepancy between the actual and the ideal.

Barnlund (1968) added: "Adequate feedback, both positive and negative, apparently contributes to the learning of new skills, the development of new insights, and the improvement of interpersonal relationships."

In order to determine what form feedback to the student clinician should take, it would seem essential to examine first the nature of the clinical process involved. The emphasis on developing objective procedures for analyzing the clinical situation has centered around three basic methods, 1) audio-visual taping, 2) audio taping. and 3) recording observed clinical behaviors onto a form which quantifies the data. References to such objective procedures are recent (0.Neil and Peterson, 1964, Dietrich, 1966, Brooks and Hannah, 1966; Miner, Prather, Kunze and Haller, 1967; Irwin and Nickles, 1970, Ryan, 1970, Boone and Steck, 1970, Boone and Prescott, 1970, Boone, $1970_{3}$. Kagan, 1970, and Schubert and Miner, 1971). As a partial answer to the dilemma of what the im- 
portant characteristics of a management session are and what needs to be related about these characteristics to the student, Kunze (1967) suggested "systematic observation." He concluded: "Once the student has developed a clear distinction between a statement of impressions and a description of behavioral events, he needs a systematic way of recording the observed happenings." One systematic way of obtaining data is through an analysis of the process of interactions.

Interaction analysis is an organized way to identify and study events which occur between two or more people. In order to accomplish this purpose, selected behavioral events are coded, identifying the behaviors under examination. Several scales have been developed to quantify the process of interactions in various settings. Simon and Boyer (1966) cited approximately seventy-eight categorizing systems used to analyze interactions in education, industry, medical training institutions, psychotherapy and in various other clinical situations. A search through the literature in the area of speech pathology and audiology for coding systems dealing with interaction analysis yields scanty results, however.

\section{INTERACTION ANALYSIS SYSTEMS FOR SPEECH CLINICIANS}

In 1970, Boone and Prescott, at the University of Denver, developed an analysis system for the purpose of 
self-evaluation and improvement of clinical skills in speech pathology.' This ten-category system, based on an operant stimulus-response paradigm, allowed the clinician to quantify his own performance. This event recording system was expanded by Prescott (1970) into a nineteen-category system which described the mode of the stimulus. Boone and Prescott (1972) speculated this type of data would eventually assist in determining "good" and "bad" clinical management in various clinical parameters. The original system consisted of five categories relating to clinician behavior and five categories relating to client behavior. The category numbers, tities, and a brief description of the Boone and Prescott System are shown in Figure 1. When using this system, the clinician places a mark $(-)$ next to the particular behavior occurring at that time. When the behaviors under observation change, another notation is made.

Almost simultaneously, the Analysis of the Behavior of the Clinician System (ABC System) was developed by Schubert and Miner (1971). This system is a similar method of describing behavioral events in 12 categories. The first eight categories pertain to clinician behavior, the next three pertain to client behavior, and the last is a joint category, Silence. The ABC System has been used to investigate clinical behavior and to assist in training student clinicians in speech pathology. Recording of the 
Category

Definition

1. EXPLAIN, DESCRIBE

Clinician describes and explains the specific goals or procedures of the session.

2. MODEI, INSTRUCTION

Clinician specifies client behavior by direct modeling or by specific request.

3. GOOD EVALUATIVE

Clinician evaluates client response and indicates a verbal or non-verbal approval.

4. BAD EVALUATIVE

Clinician evaluates client response as incorrect and gives a verbal or non-verbal disapproval.

5. NEUTRAL-SOCIAI

Clinician engages in behavior which is not therapy goal oriented.

6. CORRECT RESPONSE

Client makes a response which is correct for clinician instruction or model.

7. INCORRECT RESPONSE Client makes incorrect re告 sponse to clinician instruction or model.

8. INAPPROPRIATE-SOCIAI

Client makes response which is not appropriate for session goals.

9. GOOD SELF-EVALUATIVE

Client indicates awareness of his own correct response.

10. BAD SELF-EVALUATIVE

Client indicates awareness of his own incorrect response.

Figure 1. Boone and Prescott Ten Category System 
data, using the $A B C$ System is done at three-second intervals. The observer records a number at each timed interval which corresponds to the specific interaction which occurred immediately preceeding the recording. The $A B C$ System is shown in Figure 2.

According to Schubert and Glick (1973) who compared the two systems of recording interactions, the BoonePrescott System and the ABC'System, "When all categories from both systems were observed, it was seen that the difference in the total number of behaviors recorded was very small." From the sample recorded, 4,891 behaviors were tabulated using the Boone-Prescott System while 4,800 were recorded using the $A B C$ System.

The dissimilar categories of behavior recorded by the two systems proved important in terms of frequency of occurrence of behaviors, however. For instance, the $A B C$ Category number 12, Silence, occurred 299 times, or accounted for 6.2 percent of the total behaviors. There is no such category recorded in the Boone-Prescott System. In addition, the $A B C$ Category number 8, Using Authority, occurred 72 times, or 1.5 percent of the total behaviors. When this behavior (Using Authority) occurred it was included in the Boone-Prescott System as Category number 5. Neutral-Social.

When only the similar behavior categories of the two systems were compared, a perfect positive correlation 
existed in the rank ordering of the frequency of occurrence of behaviors. Schubert and Glick concluded that both systems have advantages depending upon the purpose for using them.

The ABC System records behavior every three seconds, regardless of the number of behaviors occurring within that time period. The Boone-Prescott System records every behavior event change as it occurs without regard to the time factor. As the data indicated, both systems appear to record similar total amount of interactions, although some obvious differences exist.

The recording of the data by means of the BoonePrescott System was done with greater ease (Schubert and Glick, 1973). This was attributed to recording behaviors as they occurred and not having to contend with a timed interval. However, the length of a single behavior was tallied using the $A B C$ System, while the same behavior was given only one notation using the Boone-Prescott System. For example, the behaviors of a clinician who read a story to the client before asking him to respond would be recorded as a number 2 (Model and Instruction) followed by a number 6 (Correct Response) using the Boone-Prescott System. This same segment of behaviors would be recorded by the ABC System as a series of 3 's (Auditory and/or Visual Stimulation) before a 9 (Client Responds Correctly). The exact number of seconds the clinician stimulated the 
Category

Definition

\begin{tabular}{|c|c|c|}
\hline 1. & $\begin{array}{l}\text { OBSERVING AND MODIPYING } \\
\text { LESSON APPROPR IATEIY }\end{array}$ & $\begin{array}{l}\text { Using response or action of the } \\
\text { client to ad just goals and/or } \\
\text { strategies }\end{array}$ \\
\hline 2. & $\begin{array}{l}\text { INSTRUCTION AND DEMON- } \\
\text { STRATION }\end{array}$ & $\begin{array}{l}\text { Process of giving Instruction } \\
\text { or demonstrating the procedures } \\
\text { to be used }\end{array}$ \\
\hline 3. & $\begin{array}{l}\text { AUDITORY AND/OR VISOAI, } \\
\text { STIMULATION }\end{array}$ & $\begin{array}{l}\text { Questions, cues, and models } \\
\text { intended to elicit a response }\end{array}$ \\
\hline & $\begin{array}{l}\text { AUDITORY AND/OR VISUNI } \\
\text { POSITIVE REINPORCEMENT OF } \\
\text { CLIENT'S CORRECT RESPONSE }\end{array}$ & $\begin{array}{l}\text { Process of giving any positive } \\
\text { response to correct cllent } \\
\text { response. }\end{array}$ \\
\hline 5 & $\begin{array}{l}\text { AUD ITORY AND/OR VISUAL NEG- } \\
\text { ATIVE RE RNFORCEMENT OP } \\
\text { CLIENT'S INCORRECT RE- } \\
\text { SPONSE }\end{array}$ & $\begin{array}{l}\text { Process of giving any negative } \\
\text { response to an incorrect } \\
\text { client response }\end{array}$ \\
\hline 6. & $\begin{array}{l}\text { AUD ITORY AND/OR VISUAL POS- } \\
\text { ITIVE RE INPORCEMENT OF } \\
\text { CIIENT'S INCORRECT RESPONSE }\end{array}$ & $\begin{array}{l}\text { Process of giving any positive } \\
\text { response to an incorrect cllent } \\
\text { response }\end{array}$ \\
\hline 7. & $\begin{array}{l}\text { CLINIC IAN RELATING IRRE- } \\
\text { LEVANT INPORMATION AND/OR } \\
\text { ASKING IRRELEVANT QUESTIONS }\end{array}$ & $\begin{array}{l}\text { Talking and/or responding } \\
\text { in a manner unrelated to changing } \\
\text { gpeech patterns }\end{array}$ \\
\hline 8. & $\begin{array}{l}\text { USING AUTHORITY OR DEMON- } \\
\text { STRATING DISAPPROVAI }\end{array}$ & $\begin{array}{l}\text { Changing social behavior from } \\
\text { unacceptable to acceptable } \\
\text { beharlor }\end{array}$ \\
\hline 9. & $\begin{array}{l}\text { CIIENT RESPONDS COR- } \\
\text { RECTLY }\end{array}$ & $\begin{array}{l}\text { Client responds appropriately, } \\
\text { meets expected level }\end{array}$ \\
\hline & $\begin{array}{l}\text { CLIENT RESPONDS IN- } \\
\text { CORRECTLY }\end{array}$ & $\begin{array}{l}\text { Client apparently tries to } \\
\text { respond approprlately but } \\
\text { response is below expected level }\end{array}$ \\
\hline & $\begin{array}{l}\text { CL IENT RELATING IRRE- } \\
\text { LEVANT INPORMATION AND/ } \\
\text { OR ASKING IRRELEVANT } \\
\text { QUESTIONS }\end{array}$ & $\begin{array}{l}\text { Talking and/or responding in a } \\
\text { manner unrelated to changing } \\
\text { speech patterns }\end{array}$ \\
\hline & SIEENCE & $\begin{array}{l}\text { Absence of verbal and relevant } \\
\text { motor behavior }\end{array}$ \\
\hline
\end{tabular}

Pigure 2. Analysis of Behavior of Cliniclans (ABC) System. 
client would be tallied, giving a much clearer indication of the time spent on a given category. Schubert (1973) concludes 8

It was apparent that the Boone-Prescott System and the $A B C$ System were very similar in providing useful information during a "typical" therapy session: however, when the session was poorly planned and carried out, the $A B C$ System gave more pertinent information in terms of amount of time spent on specific behaviors.

Schubert, Miner and Prather (1972) conducted a study using the $A B C$ System at the University of Washington in which they examined the behaviors used by beginning and more advanced student clinicians. Among other variables, they examined the importance of the position of the time segment in the total session used to record the data. They reported that the position of the 5 minute segment in the total session did not significantly affect the data when comparing the two groups.

Generally speaking, if beginning clinicians were observed to use a particular behavior more frequently than more advanced clinicians during the first five minutes, they also did so during the intermediate five minutes. The same was true of the advanced clinicians (Schubert, Miner and Prather, 1972).

It would appear, then, that the position of the time segment in the session from which data was taken was not crucial in determining representative samples of a clinician's behavior.

Schubert and Laird (1974) investigated the length of time necessary to obtain a representative sample of 
clinician-client interaction. The results of their analysis indicated that no significant differences existed between the behavioral patterns of clinician-client interaction when comparing five different three-minute segments of recorded interactions. This means that experimenters, clinical supervisors and clinicians could use data from less than five minutes of management for evaluation and be confident that they have a representative sample of clinician-client interaction during that treatment session. 
CHAPTER III

METHODS AND PROCEDURES

\section{SUBJECTS}

The subjects for this study were six beginning student clinicians in Speech Pathology at Portland State University. The group was comprised of students beginning their first term of clinical practicum Fall Term, 1974. The range of experience obtained by the clinicians prior to the study was from 0 to 2 hours. The clients were children with minor articulation disorders who ranged in age from 4 years to 18 years.

\section{Control Group}

Two of the six clinicians were randomly selected to represent the control group.

\section{Instrumentation}

Raw data was collected by utilizing the Analysis of the Behavior of the Clinician System (ABC System, Schubert and Miner. 1971). This is a coded system in which each Category's number corresponds to a specific type of clinician-client interaction behavior. Every three seconds the observer recorded the appropriate number on a Raw Data Collection Sheet (Appendix A). Behavior was tracked for 
a randomly selected consecutive five minute period during the intermediate 15 minutes of the 50 minute sessions. Each of the six clinicians was observed and data compiled for six sessions each. This procedure allowed for 3,600 recorded notations, which included 1,200 observations of control group behaviors to be compared with 2,400 observations of the experimental group's behaviors.

\section{Reliability}

The examiner attended two 2-hour training sessions with Miner, co-author of the $A B C$ System. Through the use of training films, instruction and practice, the experimenter became familiax with the recording procedures. Subsequently, practice recording from video-tapes and actual clinic sessions satisfied the examiner that proficiency had been attained using the system. Four intra-reliability checks of the number and kind of the examiner's observations were made. Randomly selected five minute intervals from a video tape of articulation sessions provided the material for establishing 94:97, 99 and 96 percent agreement, respectively, between observation segments.

\section{PROCEDURE}

The five-minute recording segments from each of six clinic sessions were recorded one week apart (Data Sessions $1,2,3,4,5$ and 6 ). The segments were randomly selected from an intermediate fifteen minutes of the total 50 minute 
sessions. Three Treatment Sessions were conducted for the experimental group. The Data Sessions coincided in time for both groups, while the treatment sessions for the experimental clinicians occurred following Data Sessions 3, 4, and 5, respectively. A schematic illustration of the sequence of the data sessions is presented below:-

Control Data Sessions: Experimental Data Sessions:

Treatment Sessions:

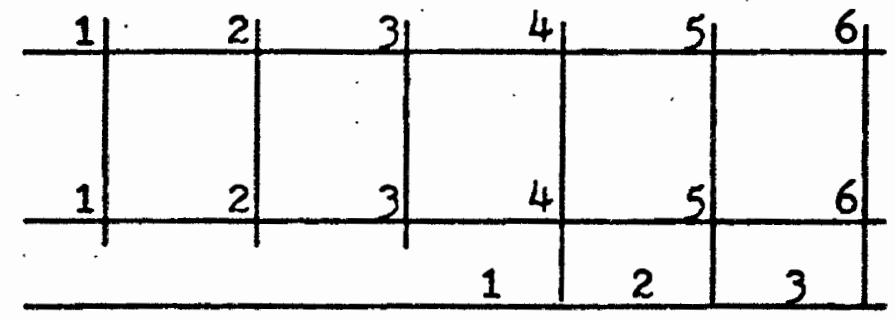

Figure 3. Schematic Illustration of Procedure

\section{Treatment Procedures}

Treatment I. Following raw data collection for Data Sessions 1, 2 and 3, the data were compiled on a Quick Analysis Form for each of the experimental clinicians (Appendix B). This showed in graph form, the percentage of the clinician's use of each category during the total 15 minute recording time. Each of the experimental group clinicians met individually with the experimenter for the Treatment I session. The clinician's Quick Analysis Form was presented to him along with a verbal definition of each of the categories on the ABC System. No further instruction was given to the clinicians suggesting areas of change or criteria for grade assignment. The supervisory staff of the clinical practicum were not present in the session 
and the students were assured the information was gathered for pilot study purposes and shared with them for their own information. In addition, the clinical supervisor was not aware of which clinicians comprised the experimental Eroup.

One week after the Treatment I session described above, each experimental clinician was again observed for a randomly selected five minutes and the behavior was again tabulated on the Raw Data Collection Sheet. This session was designated as Data Session 4.

Treatment II. This time, the Quick Analysis Form used for analyzing behaviors from Data Session 4 was given to the clinicians as soon as the treatment session was terminated. Verbal discussion was minimal for this procedure and consisted only of clarification of any of the behavioral categories tracked when the student clinician requested that information.

Treatment III. The procedure for Treatment II was repeated. using the $A B C$ information collected from Data Session 5. This session occurred one week after Data Session 4. One additional tracking. Data Session 6. occurred a week later in order to measure the results of the last intervention phase of the study.

\section{Control Group Procedure, A random consecutive 5} minute sample of interaction behavior was tracked for the control group from each of 6 sessions. These Data Sessions 
coincided in time with the experimental group's Data Sessions, though no additional feedback was given to the clinicians. They were aware that observations were made in the clinic, but were not aware that tracking was done.

\section{DATA ANAIYSIS}

Two major procedures were followed in analyzing the data obtained from the tracking. The first procedure included three groups of $t$ tests which were performed on each of the ABC System's categories. The first group of $\underline{t}$ tests was composed of data collected from Data Sessions 1 and 2 (Period I). The Control and Experimental Groups were compared in this way for each of the parameters measured by the ABC System. This comparison was mace in order to determine the pre-experimental equivalence of the two groups.

The second set of $\underline{t}$ tests was calculated using the coding information collected from Data Sessions 5 and. 6 (Period II). The 12 behavioral categories were compared for the Experimental and Control Groups in this fashion in order to determine significant differences in performance after the Experimental Group had been exposed to the Treatment Sessions. Data Sessions 3 and 4 were not included in the $t$ test comparisons in an effort to more clearly differentiate the before and after comparison of the two groups. 
The third set of $t$ tests was computed by comparing the information obtained from Period I with the information compiled from Period II for each group. The Experimental Group's use of each of the ABC System's categories was compared for Period I against Period II. In I1ke fashion, the Control Group was compared for Period I and Period.II. By using each group as its own control in this set of $t$ tests, a more longitudinal study of each group's change in performance under the two conditions of feedback was permitted.

The second major procedure used in analyzing the data also included two sets of $t$ tests. The values used for comparison were computed from the five behavioral ratios listed below. The ratios were theoretical constructs of behavior relationships that were used to determine the percentage of occurrence of $a$ specified behavior in relation to other specific behaviors. The first set of $\underline{t}$ tests was performed on the Experimental Group's use of each ratio for Period I in comparison with Period II. The second group of $t$ tests was used to compare ratio use in Period I with Period II for the Control Group. The behavioral ratios were:

1. Correct Response Ratio, is the number of Correct Responses (Category number 9) divided by the number of Correct Responses (Category 


$$
\begin{aligned}
& \text { number 9) plus the number of } \\
& \text { Incorrect Responses (Category } \\
& \text { number 10) to determine the } \\
& \text { percentage. }
\end{aligned}
$$

2. Positive Reinforcement Ratio: is the number of Positive Reinforcement of Correct Responses (Category number 4) divided by the number of Correct Responses (Category number 9) to determine the percentage.

3. Negative Reinforcement Ratio: is the number of Negative Reinforcement of Incorrect Responses (Category number 5) divided by the number of Incorrect Responses (Category number 10) to determine the percentage.

4. Inappropriate Ratio is the number of Positive Reinforcement of Incorrect Responses (Category number 6) divided by the number of Correct Responses plus the number of Incorrect Responses (Category number 9 plus Category number 10) to determine 
the percentage.

5. Socilization Ratio:

is the number of the Clini-

cian Relating Irrelevant

Information plus the number

of Client Relating Irrele-

vant Information (Categories

7. plus 11) divided by the

total number of interactions

to determine the percentage. 


\section{CHAPTER IV \\ RESULTS AND DISCUSSION}

\section{RESULTS}

Comparison of Experimental And Control Groups For Period I

The mean percentages of use of each category for the two groups are listed in Table I. The data indicated that the experimental and control groups were not pre-experimentally equivalent in all parameters. This was probably a function of the smaliness of the sample. Use of each of the categories was compared for Period I. (Data Sessions 1 and 2) for the two groups to determine their equivalence before intervention. Table II lists the results of the t tests on each of the twelve behavioral categories.

The two groups were significantly different preexperimentally in the use of Category number 7. Clinician Relating Irrelevant Information (.05 level of confidence). That is, the control clinicians related more irrelevant information during Period I than did the experimental clinicians.

For the remainder of the categories, no significant differences were found during Period I. Except for the clinician's use of irrelevant behavior, the groups appeared to be using comparable amounts of each of the behaviors 
TABLE I

MEAN PERCENTAGE OP USE OP EACH CATEGORY FOR SIX SESSIONS

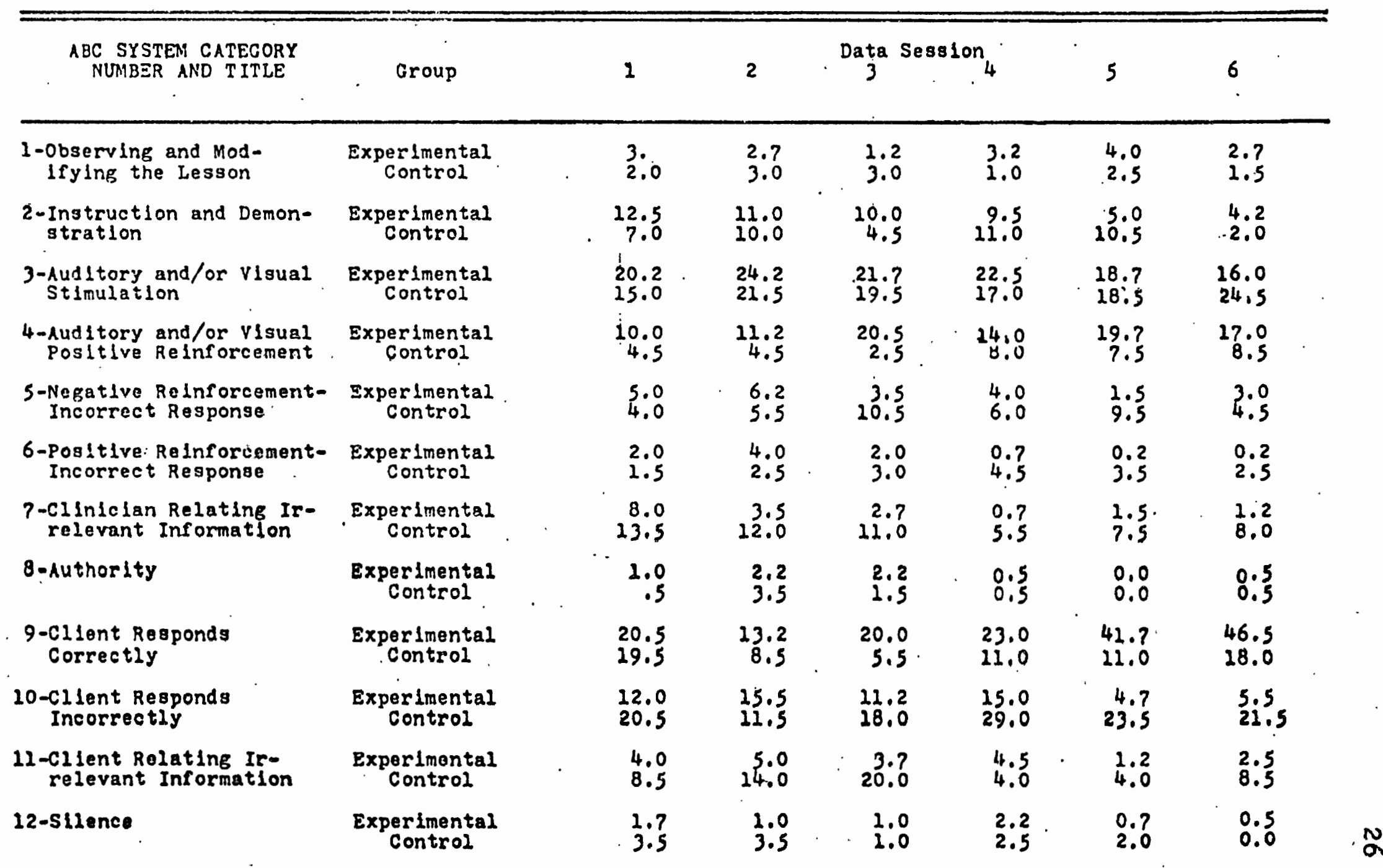


TABLE II

COMPARISON OF CONTROL AND EXPERIMENTAL GROUPS FOR PERIOD I (DATA SESSIONS 1 AND 2 )

\begin{tabular}{|c|c|c|c|c|c|c|c|}
\hline $\begin{array}{l}\text { ABC SYSTEM CATEGORY } \\
\text { NUMBER AND TITLE }\end{array}$ & $\begin{array}{l}\text { Mean } \\
\text { Control }\end{array}$ & & $\begin{array}{l}\text { S.D. } \\
\text { Control }\end{array}$ & $\begin{array}{c}\text { Mean } \\
\text { Experimental }\end{array}$ & Experimental & $\underline{\mathbf{t}}$ & $\begin{array}{c}\text { Ievel of } \\
\text { Significance }\end{array}$ \\
\hline $\begin{array}{l}\text { 1-Observing and Modlfying } \\
\text { The Lesson }\end{array}$ & 2.5 & & 3.0 & 2.875 & 3.1367 & -0.1977 & NS \\
\hline $\begin{array}{l}\text { 2- Instruction and Demon- } \\
\text { stration }\end{array}$ & 8.5 & & 6.0277 & 11.75 & 8.8600 & -0.6540 & NS \\
\hline $\begin{array}{l}\text { 3-Auditory and/or Visual } \\
\text { Stimulation }\end{array}$ & 18.25 & & 5.7373 & 22.25 & $6.2048^{\circ}$ & -1.0763 & NS \\
\hline $\begin{array}{l}\text { 4-Auditory and/or visual } \\
\text { Positive Reinforcement }\end{array}$ & 4.5 & & .5773 & 10.625 & 8.1053 & -1.4733 & NS \\
\hline $\begin{array}{l}\text { 5-Auditory and/or Visual } \\
\text { Negative Reinforcement- } \\
\text { Incorrect Response }\end{array}$ & 4.75 & . & 3.0956 & 5.625 & 1.9955 & -0.6004 & NS \\
\hline $\begin{array}{l}\text { 6-Auditory and/or Visual } \\
\text { Positive Reinforcement- } \\
\text { Incorrect Response }\end{array}$ & 2.0 & . & .8164 & 3.0 & 1.8516 & -1.0127 & NS \\
\hline $\begin{array}{l}\text { 7-cliniclan Relating Ir- } \\
\text { relevant Information - }\end{array}$ & 12.75 & & 6.2915 & 5.75 & 3.9551 & 2.3926 & .05 \\
\hline 8-Authority & 2.0 & & 2.2080 & 1.6250 & 1.5979 & .3066 & NS \\
\hline $\begin{array}{l}\text { 9-Cllent Responds } \\
\text { Correctly }\end{array}$ & 14.0 & & 10.0995 & 16.875 & 8.8064 & -0.5095 & NS \\
\hline $\begin{array}{l}\text { 10-Cllent Responds } \\
\text { Incorreotiy }\end{array}$ & 16.0 & & 5.9441 & 13.75 & 6.3639 & .5887 & NS \\
\hline $\begin{array}{l}\text { 11-client Relating Ir- } \\
\text { relevant Information }\end{array}$ & 11.25 & & 8.2613 & 4.5 & 5.9039 & 1.6454 & NS \\
\hline 12-Silence & 3.5 & & 2.3804 & 1.375 & 1.4078 & 1.9748 & NS \\
\hline
\end{tabular}


tracked using the ABC System.

Comparison of Experimental And Control Groups For Period II

A comparison of Period II (Data Sessions 5 and 6) of the two groups yielded a more marked configuration of differences than had bee' found in Period $I$. The results of the $t$ tests for this $p$ ase of the analysis are found in Table III.

The experimental and introl groups were significantly different in their use of Category number 4, Positive Reinforcement of Correct lesponse, at the .01 level of confidence. Though both gro ups used more reinforcement in Period II than they had in Pe iod I, the experimental group's use of this behavior had ccelerated to a level of statistical difference from the control group in Period II.

A difference was found at the 001 level of confidence between the groups for the use if Category number 6, Reinforcement of Incorrect Response. 'he experimental group had not differed in Period I from the control group in this area but were found to use signi. 'icantly less positive reinforcement of incorrect resporses after having been expoted to the coding information.

Also at the .01 level of confidence was the $t$ value for the use of Category number 7, Clinician Relating Irrelevant Information. The experimental group continued to relate less irrelevant information than the control 
TABLE III

COMPARISON OF CONTROL AND EXPERIMENTAL GROUPS FOR PERIOD II (DATA SESSIONS 5 AND 6)

\begin{tabular}{|c|c|c|c|c|c|c|}
\hline Category Number and Title & $\begin{array}{l}\text { Mean } \\
\text { Control }\end{array}$ & $\begin{array}{l}\text { S.D. } \\
\text { Control }\end{array}$ & $\begin{array}{l}\text { Mean } \\
\text { Experimental. }\end{array}$ & $\begin{array}{l}\text { S.D. } \\
\text { Experimental }\end{array}$ & $\underline{t}$ & $\begin{array}{l}\text { Level of } \\
\text { slgntrlcance }\end{array}$ \\
\hline $\begin{array}{l}\text { 1-Observing and Modifyling } \\
\text { The Lesson }\end{array}$ & 2.0 & 2.4494 & 3.375 & 3.422 & -0.7104 & NS \\
\hline $\begin{array}{l}\text { 2-Instruction And Demon- } \\
\text { stration }\end{array}$ & 6.25 & 5.3150 & 7.125 & 4.6117 & -0.2956 & NS \\
\hline $\begin{array}{l}\text { 3-Auditory and/or Visual } \\
\text { Stimulation }\end{array}$ & 21.5 & 4.2032 & 27.625 & 5.9024 & 1.1613 & NS \\
\hline $\begin{array}{l}\text { 4- sud 1 tory and/or Vloual } \\
\text { Poglt lve ielnforcement }\end{array}$ & 8.0 & 1.4142 & $18: 375$ & $4: 2405$ & -4.6654 & .02 \\
\hline $\begin{array}{l}\text { 5-Aud Itory and/or Visual } \\
\text { Negative Reinforcement- } \\
\text { Incorrect Response }\end{array}$ & 7.0 & 6.0553 & 2.25 & 1.2817 & 2.2253 & NS \\
\hline $\begin{array}{l}\text { 6-Auditory and/or Visual } \\
\text { Positlve Relnforcement- } \\
\text { Incorrect Response }\end{array}$ & 3.0 & 1.4142 & .25 & .4629 & 5.2854 & .001 \\
\hline $\begin{array}{l}\text { 7-clinlolan Relating ir- } \\
\text { relevant Information }\end{array}$ & .7 .75 & 3.8622 & 2.375 & 2.9955 & 3.8629 & .01 \\
\hline 8-Authority & .25 & .500 & .25 & .4629 & 0.0 & NS \\
\hline $\begin{array}{l}\text { 9-Cllent Responds } \\
\text { Correctiy }\end{array}$ & 14.5 & 5.1961 & 44.125 & 11.1283 & -4.9689 & .001 \\
\hline $\begin{array}{l}\text { 10-Cllent Responds } \\
\text { Incorrectiy }\end{array}$ & 22.5 & 1.2909 & 5.125 & 2.7998 & 21.5954 & .002 \\
\hline $\begin{array}{l}\text { 11-Cllent Relatirig Ir- } \\
\text { relevant Intormation }\end{array}$ & 6.25 & 4.1129 & 1.875 & 3.7201 & 2.8594 & NS \\
\hline 22-Sllence & 1.0 & 2.0 & .625 & .9161 & .4580 & NS \\
\hline
\end{tabular}


gxoup during Period II. This difference was maintained from Period I; however, the level of significant difference between the two groups had changed from .05 in Period I to .01 in Period II.

Two additional findings were significant at the .001 level of confidence, Category number 9, Client's Correct Response, and Category number 10, Client's Incorrect Response. During Period II, the clients of the experimental clinicians responded correctly significantly more often and responded incorrectly significantly less often than did the clients of the control group. These two categories represent a change from non-significant differences in Period I to the highest level of significant difference in Period II.

It was apparent from a visual inspection of the data that one of the two control clinicians differed from the other five clinicians in the relative use of some of the behavioral categories. This clinician appeared to use more irrelevant information, Category number $7_{0}$ and more reinforcement of incorrect responses, Category number 6 , than did the other clinicians. This factor detracts slightly from the above findings. However, since the experimental group received no special treatment during the first three sessions of the study, it was possible to compare the experimental group's performance during Data Sessions 1 and 2 (Period I) with Data Sessions 5 and 6 
(Period II). By using the experimental group as its own control, the data indicated a comparison of the group's change in performance after having been exposed to the feedback data. The control group was compared against itself for Period I and Period II also in an effort to indicate what changes in behavior the control group affected with routine supervision and maturation as the only major contributing factors. In this way the influence of the one control clinician is minimized in the data analysis.

Comparison of Period I and Period II For The Experimental Group

The statistical computations verify that the experimental group used significantly more Positive Reinforcement of Correct Responses, Category number 4, during Period II than they had during Period I. This difference was at the .05 level of confidence (See Table IV). The experimental group also used significantly less punishment or Negative Reinforcement of Incorrect Responses, Category number 5. after having been exposed to the feedback, than they had used during Period I. This difference was at the .01 level of confidence. They used less Reinforcement of Incorrect Responses, Category number 6, during the last sessions (.01 level of confidence), and related less irrelevant information, Category number 7 (.02 level of confidence) and used less Authority, Category number 8 , 
TABLE IV

CONPARIJON OP PERIOD I (DATA SESSIONS 1 AND 2) AND PERIOD II (DATA SESSIONS 5 AND 6) POR THE EXPER IMENTAL GROUP

\begin{tabular}{|c|c|c|c|c|c|c|}
\hline $\begin{array}{l}\text { ABC SYSTEIA CATEGORY } \\
\text { NUMBER AND TITLE }\end{array}$ & $\begin{array}{l}\text { Mean } \\
\text { Period I }\end{array}$ & $\begin{array}{l}\text { S.D. } \\
\text { Period I }\end{array}$ & $\begin{array}{l}\text { Mean } \\
\text { Perlod II }\end{array}$ & $\begin{array}{l}\text { SiD. } \\
\text { Period II }\end{array}$ & $\underline{t}$ & $\begin{array}{l}\text { Level of } \\
\text { Signiflcance }\end{array}$ \\
\hline $\begin{array}{l}\text { 2-Instruction and Demon- } \\
\text { stration }\end{array}$ & $\cdot 12.75$ & 8.860 & 7.1250 & 4.6127 & 1.3096 & NS \\
\hline $\begin{array}{l}\text { 4-Auditory and/or Vlsual } \\
\text { Positive Relnforcement }\end{array}$ & 10.625 & 8.1053 & 28.375 & 4.2405 & -2.3962 & .05 \\
\hline $\begin{array}{l}\text { 5-Auditory and/or Visual } \\
\text { Negative Re Inforcement- } \\
\text { Incorrect Response }\end{array}$ & 5.625 & 1.9955 & 2.25 & 1.2817 & 4.0249 & .01 \\
\hline 8-Author Ity & 2.625 & 2.5979 & .25 & .4629 & 2.3376 & .05 \\
\hline $\begin{array}{l}\text { 9-Cllent Responds } \\
\text { Correctly }\end{array}$ & 26.875 & 8.8064 & 44.125 & 11.1283 : & .5 .4311 & .001 \\
\hline $\begin{array}{l}\text { 10-CIlent iesponds } \\
\text { Incorrectly }\end{array}$ & 23.75 & 6.3639 & 5.1250 & 2.7998 & $3.508 ?$ & .01 \\
\hline $\begin{array}{l}\text { 12-cllent Relating Ir- } \\
\text { relevant Information }\end{array}$ & 4.5 & 5.9039 & 2.8750 & 3.7201 & 2.0639 & NS \\
\hline 22-S1Lence & 2.375 & 1.4078 & .6250 & .9161 & 1.2629 & NS \\
\hline
\end{tabular}


(.05 level of confidence) than they had during the initial sessions.

In addition, the clients of the experimental group differed significantly from themselves by responding correctly, Category number 9, more often and responding incorrectly, Category number 10, less often during the last sessions than they had during the initial sessions. The differences in use of these categories were at the .001 level of confidence for Category number 9 and at the .01 level for Category number 10.

Comparison of Period I And Period II For The Control Group

The control group differed from themselves by the end of the study in only one of the 12 Categories (Table V). The control clinicians used significantly more Positive Reinforcement of Correct Responses, Category number 4, during Period II than they had during Period I (.01 level of confidence).

It is interesting to note that the $t$ test for the control group's use of Positive Reinforcement, Category number 4, yields a significant difference at the .01 level of confidence, while the experimental group differed from themselves in this category's use only at the .05 level of significance. The $t$ test reflects the control group's increase of the use of Positive Reinforcement from 4.5 percent in Data Session 1 to 8.5 percent in Data Session 6. The experimental group used appreciably more time reinforc- 
TABLE Y

COMPARISON OP PERIOD I (DATA SESIIONS 1 AND 2) AND PERIOD II (DATA SESSIONS 5 AND 6) POR CONTROL GROUP

\begin{tabular}{|c|c|c|c|c|c|c|}
\hline $\begin{array}{l}\text { ABC SYSTEM CATEGORY } \\
\text { NUMBER AND TITLE }\end{array}$ & $\begin{array}{l}\text { Mean } \\
\text { Perlod I }\end{array}$ & Period I & $\begin{array}{l}\text { Mean } \\
\text { Perlod II }\end{array}$ & Period II & $\underline{t}$ & $\begin{array}{c}\text { Level of } \\
\text { Sleniflcance }\end{array}$ \\
\hline $\begin{array}{l}1-\text { Observing and Modlfylng } \\
\text { The Lesson }\end{array}$ & 2.5 & 3.0 & 2.0 & 2.4494 & 0.2581 & NS \\
\hline $\begin{array}{l}\text { 2-Instruction and Demon- } \\
\text { stration }\end{array}$ & 8.5 & 6.0277 & 6.25 &. .5315 & 0.5599 & NS \\
\hline $\begin{array}{l}\text { 3-kud } 1 \text { tory and/or Vlsual } \\
\text { Stimulation }\end{array}$ & 28.25 & 5.7373 & $22.5^{-}$ & 4.2031 & -0.9139 & NS \\
\hline $\begin{array}{l}\text { 4-Auditory and/or Visual } \\
\text { Positive Reinforcement }\end{array}$ & 4.5 & .5773 & 8.0 & 1.4142 & -4.5825 & .01 \\
\hline $\begin{array}{l}\text { 5-Aud Itory and/or Visual } \\
\text { Negatlive Reinforcement- } \\
\text { Incorrect Response }\end{array}$ & 4.75 & 3.0956 & 7.0 & 6.0553 & -0.6616 & NS \\
\hline $\begin{array}{l}\text { 6-Auditory and/or Visual } \\
\text { Positlve Reinforcement- } \\
\text { Incorrect Response }\end{array}$ & 2.0 & .8164 & 3.0 & 1.4142 & -1.2247 & NS \\
\hline $\begin{array}{c}\text { 7-clinlclan Relating Ir- } \\
\text { relevant Information }\end{array}$ & 22.75 & 6.2915 & 7.75 & 3.8622 & 1.3545 & NS \\
\hline 8 -Author Ity & 2.0 & 2.7080 & 0.25 & 0.5 & 1.2709 & NS \\
\hline $\begin{array}{l}\text { 9-Cllent Responds } \\
\text { Correctly }\end{array}$ & 24.0 & 20.0995 & 14.5 & 5.1961 & .0880 & NS \\
\hline $\begin{array}{l}\text { 10-Cllent Responds } \\
\text { Incorrectly }\end{array}$ & 26.0 & 5.91441 & .22 .5 & 1.2909 & -2.1372 & NS \\
\hline $\begin{array}{l}\text { 11-Cllent Relating Ir- } \\
\text { relevant Information }\end{array}$ & 11.25 & 8.2613 & 6.25 & 4.1129 & 1.0835 & NS \\
\hline 12-S1Lence & 3.5 & 2.3804 & 2,0 & . 2.0 & 1.6081 & NS \\
\hline
\end{tabular}


ing correct responses, 17 percent, during Data Session 6 , but the change from Data Session 1 of 10 percent is less significant statistically than the control group's change.

Comparison of Interaction Ratios For Periods I And II

Of the five interaction ratios listed in Chapter. III, t test computations yielded significant differences for the experimental group in two of the comparisons (Table VI). No significant differences were obtained for the control group in any of the ratios (Table VII).

The three ratios which did not change significantly for either group over the two time periods were the Positive Reinforcement Ratio (Number of Positive Reinforcement of Correct Responses divided by the number of Correct Responses or $4 / 9$ ), the Socialization Ratio (Number of Clinician Relating Irrelevant Information plus number of Client Relating Irrelevant Information divided by the total number of interactions, or $7+11 /$ total interactions), and the Negative Reinforcement Ratio (Number of Negative Reinforcement of Incorrect Response divided by the number of Incorrect Responses or 5/10). Apparently neither routine supervision and maturation nor the coding feedback affected. appreciable change in the use of these combinations of behaviors.

The two ratios which did show change in interaction patterns for the experimental group were the Correct Response Ratio (Number of Correct Responses divided by the 
- TABLE VI

COMPARISON OF INTERACTION RATIOS FOR PERIOD I AND

PERIOD II FOR THE EXPER IMENTAL GROUP

ABC. SYSTEM RATIO NUMBERS
AND TITLES $\quad \begin{gathered}\text { Mean } \\ \text { Period I }\end{gathered}$ Period I $\quad \begin{gathered}\text { Mean } \\ \text { Perlod II Period II }\end{gathered}$

Correct Hegponse Ratio:

Number of Correct Responses

dlvided by Number of Correct

iesponses plus Number of In-

correct Responses or $9 / 9+10$

.2661

.8939

.0499

$-4.2233$

.01

Soclalization Ratlo: Number

of Cilnician Relating Irrelevant Information plus Number of client Relating Irrelevant Information divided by Total number of Interactions or $7+11 /$ Total Interactions

Inapproprlate Ratlo' Number Incorrect Responses divided by Number of Correct Responses plus Number of IncorrectiReplus Number of Incor

Negative Re Inforcement Ratlor Number of Negative Reinforcement of Incorrect Responses divided by Number of Incorr. ect Responses or $5 / 10$

\section{Positiye Re Inforcement Ratior} Number of Positive Relnforcement of Correct Responses divided by Number of Correct Responses or $4 / 9$ 
TABLE VII

COMPARISON OP INTERACTION RATIOS POR PERIOD I

AND PERIOD II POR THE CONTROL GROUP

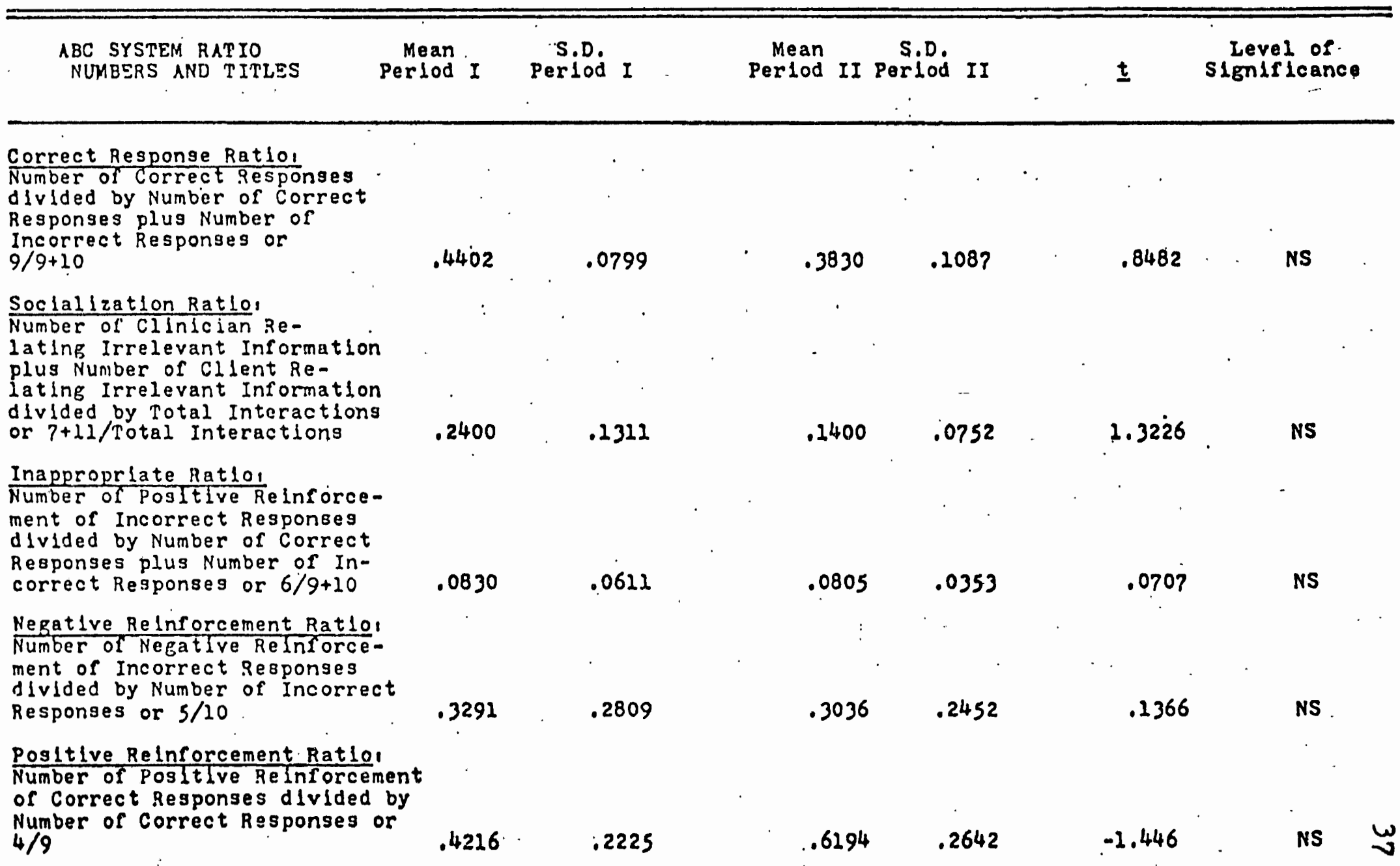


number of Correct Responses plus the number of Incorrect Responses or $9 / 9+10$ ) and the Inappropriate Ratio (Number of Reinforcement of Incorrect Responses divided by the number of Correct Responses plus the number of Incorrect Responses or $6 / 9+10)$.

The difference in the use of the Correct Response Ratio was found to be at the .01 level of confidence. This reflects the experimental group's obtaining significantly more positive responses of the total correct and incorrect responses in Period II than they had in Period I. The difference in the use of the Inappropriate Ratio was also calculated at the .01 level of confidence. The finding was attributable to the combination of less frequent inappropriate reinforcement, less frequent incorrect responses and more frequent correct responses by the end of the study. 


\section{DISCUSSION}

\section{Significant Differences}

The null hypothesis, that there would be no signi-

ficant differences between the control and experimental clinicians by the end of the study, was rejected. The two groups of clinicians demonstrated significant differences in the behaviors tracked during the last two data sessions. First the commonalities of the two groups will be discussed.

Both groups when compared to themselves showed a significant increase in the use of positive reinforcement of correct responses. In addition, the clients of the control group approached a significant difference when compared to themselves for Periods I and II in the behavior labeled Category number 10, Client Responds Incorrectly; however, the clients for the experimental group were sigrificantly different from themselves in this behavior at the .01 level of confidence. One can assume that clinical experience and traditional supervision of both groups would account for at least some of this growth. The design of this study allowed for the normal routine of clinical practicum to proceed for both groups, while the additional feedback from the $A B C$ System was added for the experimental group. The fact that neither group was deprived of traditional supervision makes the 
significant differences between the groups all the more impressive. It is not surprising that the control group demonstrated growth during the six sessions of the study-indeed one would be at a loss to explain a lack of behavior change in response to the clinical supervision which has shaped the management skills of the majority of those practicing in our profession. The impressive growth of the experimental clinicians in response to minimal exposure to the $A B C$ System exceeds even the expectations of the examiner.

Exposure to the coding feedback seems to have accelerated the growth of the experimental group. Furthermore, all of the statistically significant changes were in the direction supervisors generally encourage. That is, the experimental group used more reinforcement, less punishment, reinforced incorrect responses less frequently, related irrelevant information less often and used authority less often by the end of the study. Most importantly, the clients of the experimental group responded correctly more often and incorrectly less often than the control subjects by the end of the study. The reaction to the $A B C$ System feedback on the part of the experimental clinicians as indicated by their behavior change, was very promising. One wonders whether this result was because of or in spite of the unobtrusive manner in which the feedback was presented to them. For 
the clinicians in this study were under no supervisory pressure to respond to the feedback. In fact, they were free to ignore the data completely. As the study progressed, the examiner developed the clinical feeling that the design allowed for the beginning clinician to formulate his own hypotheses for improving his clinical skills and to initiate behavior changes accordingly.

The theory could be tested by comparing the behavior change of clinicians who received the $A B C$ System feedback in a more formalized manner from their supervisor with the indirect method employed in the current study. The additional pressure resulting from the judgements of the supervisor due to the covert grade threat may prove either to accelerate the growth of the clinician or be counter productive toward that end.

\section{Additional Findings}

Interestingly, neither group changed signiffeantly in the use of five of the categories: Category number 1 , Modifying the Lesson, Category number 2, Instructing and Demonstrating, Category number 3, Stimulating, Category number 11, Client Relating Irrelevant Information and Category number 12, Silence. The smallness of the present sample together with the limited time sample of six weeks prevents conclusive statements concerning these findings: however, some tentative explanations are suggested. 
The clinical intuition of the examiner suggests that use of Category number 1, Observing and Modifying the Lesson, may increase with the experience of the clinician. Both groups of this study were inexperienced clinicians, who it seemed relied heavily on the preset procedures and objectives written in their lesson plans. The hypothesis that Modifying the Lesson and clinical experience are related is supported by previous research in which schubert and Miner (1971) found experienced clinicians differed significantly from inexperienced clinicians in the adapting of lessons.

In respect to some of the other statistically insignificant results, an interaction of some of the behaviors is suggested. One would expect Categories 2 and 3. Instruction and Stimulation, to decrease as Category number 9, Correct Responses, increased. That is, the amount of time spent in instructing and modeling should logically decrease as the client progresses in his articulatory ability. This relationship did exist for the experimental group. Use of Instruction and Stimulation decreased as the clients' correct responses increased, though not dramatically enough to reach the level required for statistical significance. The control group demonstrated no such decline in the use of Instruction and Stimulation, however, their steady use of these two categories is understandable in relation to the responses they 
were obtaining from their clients. Perhaps since the clients of: the control group were not demonstrating articulatory growth as measured by correct responses (Category number 9), and continued to respond incorrectly at a high level (Category number 10); the clinicians were unable to reduce their instruction and modeling. The system did not permit a judgement of the quality of the instruction used by the clinicians, which might have been a factor as well.

Category number 11, Client Relating Irrelevant Information, would appear to be important in determining the amount of time allowed for socilization and could additionaliy be used as an informal measure of carryover of a particular articulatory skill. Since neither the control nor the experimental group of this study changed appreciably in the use of this category, one is again intrigued about this behavior's use in relation to the experience of the clinician. More likely, the client's relating irrelevant information is simply an indication of the inexperience of the clinician. The Schubert and Miner Study (1971) found the clients of the experienced clinicians used significantly less of this behavior than those of the inexperienced clinicians. It would appear, then, that experience in the clinical situation may be a variable in determining the amount of time the client spends relating information irrelevant to the clinical task. 
The final category which did not discriminate between the two groups nor between time periods was Category number 12, Silence. Although this category may be of importance in examining the clinical interactions in the management of other treatment parameters, it did not contribute in any measurable degree to the management of articulation disorders which were tracked in this study. This particular behavior may prove to be of clinical importance when analyzing the interaction patterns and their effects on certain clients when "time-out" procedures are used, or when the latency of a response is under examination.

The examiner also observed subtle behaviors which were not specifically included in the ABC System's categories. Future investigation of such things as the clinician's facial gestures, eye contact, voice quality and body postures may determine which, if any, of these may contribute positively or negatively to the therapeutic process. Also, some judgement as to the magnitude of reinforcement or punishment may be of clinical importance.

\section{Comparison With Previous Research}

It is interesting to compare the positive correlations between the performance of the clinicians in this study and the performance of the clinicians in previous studies using the ABC System. The experimental clinicians 
of this study compared favorably with experienced ciinicians of the Schubert and Miner Study (19?1) suggesting that systematic feedback of the $A B C$ System data facilitates growth on the part of inexperienced clinicians.

The Schubert study compared 10 beginning clinicians with less than 12 hours of clinical experience (Class I Clinicians) to 10 clinicians with more than 50 but less than 60 hours of experience (Class II CIinicians). The results indicated the two groups differed significantly at the .05 level of confidence in the use of all of the behavioral categories except number 3 and number 12. That is, as in the present study, both groups used a similar amount of Stimulation and of Silence.

Pearson Product Moment Correlations revealed a positive coefficient of .96441 between the experimental subjects of this study for Data Sessions 4, 5 and 6 and the Class II or experienced subjects of the schubert study. Guilford (1956) suggests this kind of a coefficient indi-. cates a very high correlation reflecting a very dependable relationship.

The coefficient between the control clinicians of this study and the Class I or inexperienced clinicians of the Schubert was +.3995 . The control clinicians correlated essentially the same $(+.4005)$ with the Class II clinicians of the Schubert Study. Guilford (1956) judges these scores to be in the range of low correlation indi- 
cative of a definite but small relationship. These coefficients seem to support the hypothesis of the present study, that is, feedback of systematically recorded behavioral data increases the rate of change of beginning clinicians. In this study beginning clinicians more closely approximated the performance of their experienced counterparts than the control group after having been exposed to the data only three times.

Both the Class II Clinicians of the Schubert Study and the experimental clinicians of the present study differ from the Class I clinicians of the Schubert study and the control clinicians of the current study in the following ways, They modified the lesson more often, spent less time instructing and demonstrating, reinforced correct responses more frequently, used proportionally more punishment of incorrect responses and positively reinforced incorrect responses less often. Additionally, the Class II Schubert and Experimental Clinicians related irrelevent information less frequently and used authority less often than their inexperienced and control counterparts, and the clients of the Class II and experimental clinicians responded more frequently correctly and less frequently incorrectly as well as related less irrelevant information than did the clients of the inexperienced clinicians of both studies (see Table VIII).

In summary, experience in clinical practicum and 
TABLE VIII

MEAN PERCENTAGE OF OCCURANCE OF A PARTICULAR EEKAVIOR

WHEN COHPARING CLASS I AND CLASS II CLINICIANS OP

THE SCHUBERT SPUDY (1971) VITH EXPER IMENTAL

AND CONTROL CLINICIANS FOR DATA SESSIONS

4,5 AND 6

\begin{tabular}{|c|c|c|c|c|}
\hline $\begin{array}{l}\text { AEC SYSTEO CATEGORY } \\
\text { NUMBER AND TITIE }\end{array}$ & $\begin{array}{l}\text { CIass I } \\
\text { Schubert }\end{array}$ & $\begin{array}{l}\text { Control } \\
\text { clinicians }\end{array}$ & $\begin{array}{l}\text { Class II } \\
\text { Schubert }\end{array}$ & $\begin{array}{l}\text { Experimental } \\
\text { Clinicians }\end{array}$ \\
\hline $\begin{array}{l}\text { 1-observing and Modifying } \\
\text { The Lesson }\end{array}$ & .6 & 1.6 & 1.2 & 3.3 \\
\hline $\begin{array}{l}\text { 2-Instruction and Demon- } \\
\text { stration }\end{array}$ & 9.9 & 7.8 & 8.5 & 6.2 \\
\hline $\begin{array}{l}\text { 3-Auditory and/or visual } \\
\text { Stimulation }\end{array}$ & 18.9 & 20.0 & 17.5 & 19.2 \\
\hline $\begin{array}{l}\text { 4-Auditory and/or Visual } \\
\text { Positive Reinforcement }\end{array}$ & 12.4 & 8.0 & 13.6 & 16.9 \\
\hline $\begin{array}{l}\text { 5-:egative Reinforcement- } \\
\text { Incorrect Response }\end{array}$ & 1.9 & 6.6 & 3.1 & 2.8 \\
\hline $\begin{array}{l}\text { 6-Positive Reinforcement- } \\
\text { Incorrect Response }\end{array}$ & .8 & 3.5 & .5 & .4 \\
\hline $\begin{array}{l}\text { 7- } \text { - inician Relating Ir- } \\
\text { relevant Information }\end{array}$ & 4.6 & 7.0 & 2.8 & 1.1 \\
\hline 8-Authority & 2.8 & $\cdot 3$ & 2.0 & .3 \\
\hline $\begin{array}{l}\text { 9-Client Responds } \\
\text { Correctly }\end{array}$ & 30.5 & 13.3 & 33.2 & 37.0 \\
\hline $\begin{array}{l}\text { 10-Client Responds } \\
\text { Incorrectly }\end{array}$ & 2.2 & 24.6 & 4.1 & 8.4 \\
\hline $\begin{array}{l}\text { 11-Client Relating Ir- } \\
\text { relevant Information }\end{array}$ & 8.9 & 5.5 & 6.8 & 2.7 \\
\hline 12-Silence & 6.5 & 1.5 & 6.7 & 1.1 \\
\hline
\end{tabular}


the exposure to the coding feedback appear to correlate with interaction patterns as measured with the ABC System. The experimental subjects of this study and the more experienced subjects of the Schubert Study approached the same patterns of use of the behavioral categories. 
CHAPTER V

SUMMARY AND IMPLICATIONS

\section{SUMMARY}

The major goal of supervisors in the area of Speech Pathology is to help student clinicians improve efficiency and effectiveness in attaining a therapeutic goal. This study was designed to provide systematic feedback of recorded data to student clinicians to determine the effect of a particular supervisory instrument on the future performance of inexperienced clinicians. The subjects for. this study were six beginning student clinicians in Speech Pathology at Portland State University, two of which were randomly selected to represent the control group.

All of the clinicians were observed for a randomly selected consecutive five-minute period from each of six management sessions. During these observations a content analysis was made of the interactions between the clinicians and their clients. The Analysis of Behavior of the Clinician ( $A B C$ ) System, developed by Schubert and Miner (1971) was used to record interactions on a three-second interval schedule. The observation sessions for the control group coincided in time with the experimental group's observation sessions, though no feedback was given to the 
control clinicians and they were unaware that tracking was done.

All of the observations were recorded one week apart and designated as Data Sessions 1,2,3,4,5 and 6. Pre-experimental equivalence of the control and experimental groups was measured by comparing the behaviors observed during the first two Data Sessions.

The experimental group was involved in three Treatment Sessions in addition to the traditional supervision which both groups received. Treatment I followed Data Session 3 and consisted of presenting the experimental clinicians with a composite graph of their interaction profiles that was derived from the $A B C$ System information gathered from the first three Data Sessions and a verbal definition of each of the System's twelve behavioral categories. No further instruction or advice was given to the clinicians such as suggesting areas of change or criteria for evaluation. In addition, the supervisor of the clinic was not aware of which clinicians composed the experimental group.

A graph compiled from the behaviors tracked from Data Session 4 one week later was presented to the experimental clinicians immediately following the session as the Treatment II phase of the experiment. The procedure was repeated for Treatment III, using interactions recorded from Data Session 5. One additional session wes 
observed and tracked a week later, Data Session 6, but the information was not shared with the clinicians. This session was tracked in order to measure the results of the last intervention phase of the study.

The results indicated that systematic feedback to student clinicians using the $A B C$ System positively affected change in their behavior beyond maturation and routine supervision. The experimental clinicians differed from their own baseline performance and the control clinicians. performance during the last two data sessions in four parameters. They used significantly more positive reinforcement and significantly less reinforcement of incorrect responses, less irrelevant behavior and less punishment. The clients of the experimental group responded with significantly more correct responses and significantly less incorrect responses than the clients of the control group during the last two sessions of the study.

\section{IMPLICATIONS}

\section{Implications For Clinical Training}

The current study as well as previous research based on observational systems suggest the use of such systems for the advancement and evaluation of student clinicians. The use of an observation system such as the ABC System by supervisors could provide a more objective means for evaluating and shaping the student's clinical skills by 
focusing attention of the clinician-client behaviors which prove effective in the treatment situation. This process would also deemphasize the supervisor's use of nonspecific evaluation criteria as well as provide the basis for the student's development of sound and objective self-evaluation criteria in the future.

The high intra-judge reliability found in this study as well as the random use of five-minute segments of the sessions as accurate representations of an entire treatment session should allow supervisors to obtain a profile of the student's management in a much more efficient manner than has been required in the past. It would also seem possible to analyze ongoing records of behavioral patterns rather than clinical clock hours to identify the competency of the student who is striving for clinical certification.

A totally different consideration is the possibility of teaching prospective clinicians to use the $A B C$ System for directed observations. It is possible that a student would be thus better prepared for clinical practicum by having to identify and familiarize himself with the clinical behaviors he will be expected to use. With this kind of a background, the beginning clinician might be able. to acquire expected skills more rapidly, become more objective about his own behavior and be more understanding and receptive to constructive criticism. 
Many questions remain to be answered regarding the clinician-client relationship during the period of treatment. The use of observation systems could help determine what kinds of interaction patterns describe the most efficient management techniques for various communication disorders.

By analyzing the relationships existing between behavioral changes of the clinician and the progress of the clients, one could better plan the optimal course of treatment. For change in behavior depends upon a sequence of events, rather than isolated behaviors. For example. an analysis of the sequence of behaviors cauld determine the most effective reinforcement for the client.

\section{Implications For Clinical Research}

In order to develop substitute criteria for the clock hours requirement for clinical competency, questions such as the following need investigation: How comparable are the clinician-client behavior patterns of beginning clinicians rated as "proficient" to those of experienced clinicians with the same rating? Does any pattern of interaction or ratio of particular behaviors shown by the student clinician seem to predict success when the clinician is employed professionaliy? Does the rate of change in behavior patterns of the student clinician predict future success? 
A revealing follow-up study to the present one would be an analysis of the behaviors of beginning clinicians exposed to the coding feedback with specific suggestions for change based on the patterns of interaction observed. The results of their subsequent interaction patterns could then be compared with those of students nearing the conclusion of their clinical training.

It would seem profitable as well, to know what differences occur in student growth when the system is used only by a supervisor, only by a student, or by both student and supervisor. The possibilities for practical use as well as extended research in clinical supervision seem unlimited. 


\section{REFERENCES}

Anderson, J. I. Status of College and University Programs of Practicum in the Schools. ASHA. 15, 60-65. (February, 1973).

Barnlund, Dean C., Interpersonal Communication: Survey and Studies. Boston; Houghton Mifflin Company (1968).

Black, M., Miller, A. E., Andersion, J. I., and Coates, N. H., Supervision of Speech and Hearing Programs. J. Speech Hearing Dis., Mono. Supp. 8, 22-32, (June, 1961).

Boone, D. R.. A Close Look at the Clinical Process. Conference on Supervision of Speech and Hearing Programs in the Schools. Bloomington, Ind.: Indiana University, (1970).

Boone, D. R. and Goldberg, A. A., An Experimental Study of the Clinical. Acquisition of Behavioral Principles by Videotape Self-Confrontation. Final Report to U.S. Office of Education (OG 807139-2814), Div. of Research, Bureau of Education of the Handicapped, University of Denver, Denver, (1969).

Boone, D. R. and Prescott, T. E., Audiotape and Videotape Self-Confrontation Manual. Denver, Colo.: University of Denver, (1970).

Boone, D. R. and Prescott, T. E., Content and Sequence Analyses of Speech and Hearing Therapy. ASHA, 14. 58-62. February, (1972).

Boone, $D . R$, and Stech, E. I., The Development of Clinical Sxilis in Speech Pathology by Audiotape and Videotape Self-Confrontation. Final report to U.S. Office of Education (OEG-9-071318-2814). Division of Research, Bureau of Education of the Handicapped, University of Denver, Denver, (1970).

Brooks, R. J. and Hannah, E. P. A Tool for Clinical Supervision. J. Speech Hearing Dis., 31, 383-387. (Nov., 1966).

Darley, F. I. Clinical Praining for Full-Time Clinical Service, A Neglected Obligation. ASHA, 11, 143-48, (April, 1969). 
Dietrich, W. M. Use of Videotape in Teaching Clinical Skills. Volta Rev.. 644-647, (1966).

Guilford, J. P. Fundamental Statistics in Psychology and Education, New York: McGraw-Hill Co.. Inc. (1956).

Haller, R. Supervisor's Criteria for Evaluating Students; Performance in Clinical Practicum Activities. In Miner, A. (ed.), A Symposium: Improving Supervision of Clinical Practicu.. ASHA, 9, 479-481, (1967).

Halfond, Murray M. Clinical Supervision--Stepchild in Training. ASHA, 6, 441-445, (1964).

Irwin, R. B. and Nickles, A. A. The Use of Audiovisual Fizms in Supervised Observation. ASHA, 12, 363-367, (dug., 1970).

Kagan, N. Human Relationships in Supervision. Conference on Supervision of Speech and Hearing Programs in the Schools. Bloomington, Ind.: Indiana. University, $(1970)$.

Kunze, I. Program for Training in Behavioral observation. In Miner, A. (ed.), A Symposium: Improving Supervision of Clinical Practicum. ASHA, 9, 473-476, (Dec., 1967).

Miner, A. Standards for Quality Supervision of Clinical Practicum. In Miner, A. (ed.), A Symposium: Improving Supervision of Clinical Practicum. ASHA, 9, 471-472, (Dec., 1967).

O'Neill, John J., and Peterson, H. A. The Use of Closed Circuit Television in a Clinical Speech Training Program. ASHA, 6, 445-448, (1964).

Prather, E, Approach to Clinical Supervision. In Miner, A. (ed.), A Symposium: Improving Supervision of Clinical Practicum. ASHA. 9, 472-473, (Dec., 1967).

Prescott, T. E. The Development of a Methodology for Describing Speech Therapy. Unpublished doctoral dissertation: Denver, Colorado, University of Denver, (1970).

Rees, M., and Smith, G. Supervised School Experience For Student Clinicians. ASHA, 9, 251-256. (July, 1967).

Rogers, Carl R. On Becoming a Person. Boston, Houghton Mifflin Company. (1961). 
Ryan, B. P. The Use of Videotape Recording (VTR) in University Speech Pathology and Audiology Training Centers. ASHA, 12, 555-556, (Nov., 1970).

Schubert, G. W. and Glick, A. A Comparison of Two Methods of Recording and Analyzing Student Clinician Behaviors in Speech Pathology and Audiology; A Behavior Based Procedure (Boone 10 Category System) and the Analysis of Behavior of Clinicians ( $A B C$ ) System. Paper presented at the American Speech and Hearing Association Convention. Detroit, Michigan, (October, 1973).

Schubert, G. W. and Laird, B. A. Length of Time Necessary to Obtain a Representative Sample of Clinician-Client Interaction. Paper presented at the American Speech and Hearing Association Convention. Las Vegas, Nevada, (Nov., 1974).

Schubert, G. W., and Miner, A. Modification of Flanders' Interaction Analysis Categories for Observation in Speech Therapy. Paper presented at the American Speech and Hearing Association Convention, Chicago, III.., (Nov., 1971).

Schubert, G. W., Miner, A. and Prather, E, A Comparison of Student Clinicians' Behaviors as Measured by the Analysis of Behavior of Clinician (ABC) System. Paper presented at the American Speech and Hearing Association Convention. San Francisco, California, (Nov., 1972).

Schubert, G: W.; Miner, A. L., and Till, J. A. The Analysis of Behavior of Clinicians (ABC) System. University of North Dakota Press, (1973).

Simon, A. and Boyer, E. G., (eds.), Mirrors of Behavior. Fhiladelphia: Research for Better Schools, Inc.. (1967).

Stace, A. C. and Drexler, A. B. Special Training for Supervisors of Student CIinicians: What Private Speech and Hearing Centers Do and Think About Training Their Supervisors. ASHA, 11, 318-320, (July, 1969).

Van Riper, C. Supervision of Clinical Practice. ASHA, 7. 75-77, (March, 1965). 
APPENDIX A

RAW DATA COLLECTION SHEET

A. B. c. reooro Past Treativenf cliwicuns: $\left.{ }_{5}^{1} 2^{3}\right)^{4}$ osservez

\begin{tabular}{|c|c|c|c|c|c|c|c|c|c|c|c|c|c|c|c|c|c|c|}
\hline & & & & & & & & & & & & & & & & & & \\
\hline $3 \mid$ & & & 10 & $|2|$ & & $|10|$ & & 10 & & $10 \mid$ & & 10 & 21 & $3 \mid$ & & 4 & & 013 \\
\hline 91 & $14 \mid$ & 3 & 10 & & 10 & 3 & 10 & 3 & 9 & $<$ & 3 & 9 & $<1$ & 3 & 9 & & & 2 \\
\hline 3 & 9 & 3 & 9 & 4 & 3 & 10 & $\pi$ & 3 & & 4 & 21 & 2 & 2 & 31 & b) & & & 4 \\
\hline 31 & 9 & 3 & 9 & 4 & 3 & 10 & 3 & 10 & & & & 9 & 4 & J & & $\overline{1}$ & 4 & 99 \\
\hline 41 & & 10 & 3 & 9 & 4 & 3 & 10 & & & & 4 & 3 & & 5 & & & & 213 \\
\hline
\end{tabular}

$917 \quad 2018$ i1 $1: 00$

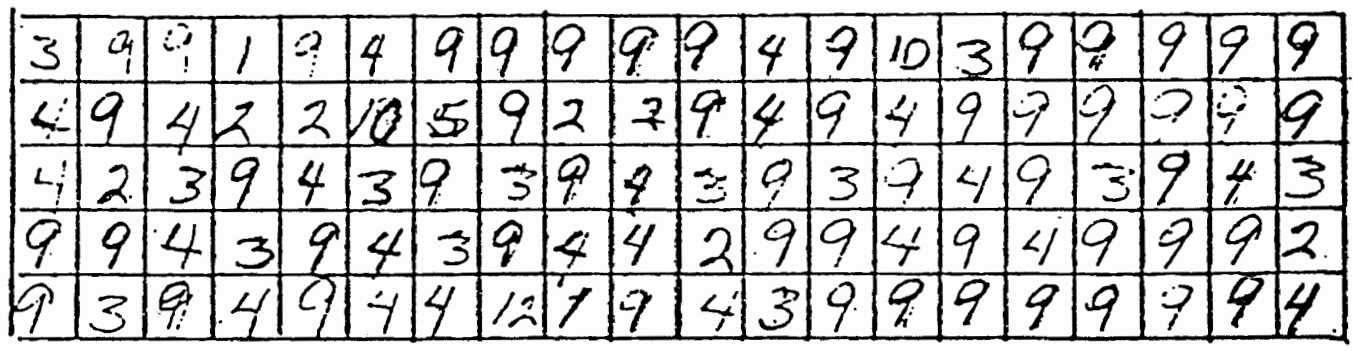

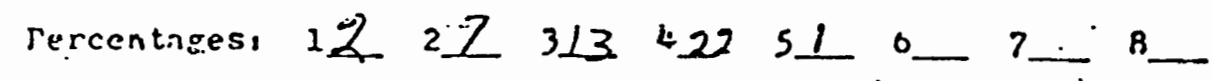

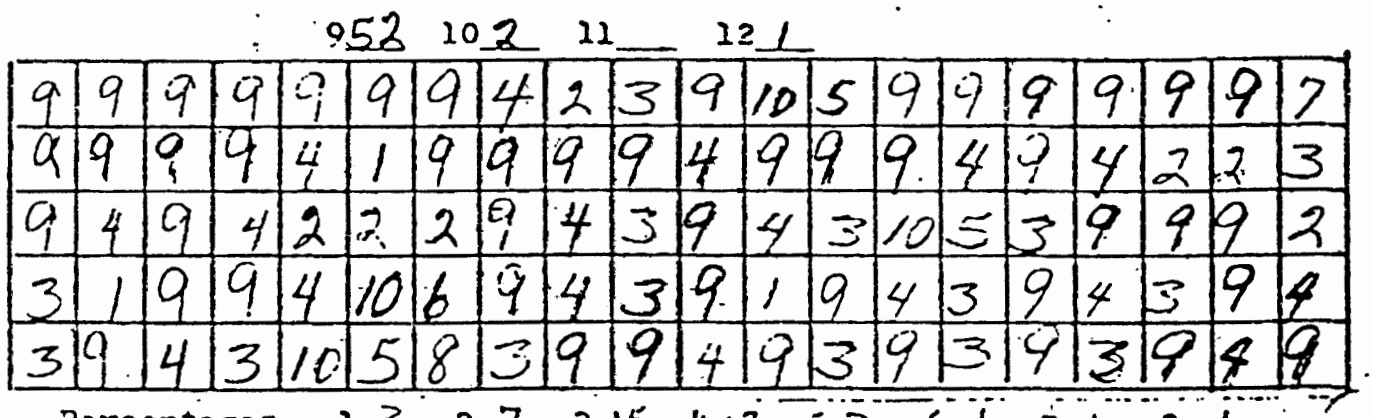

Percentapesi $1327 \quad 31541753617 \perp 81$ $94810422-12$ 
APPENDIX E

QUICX ANALYSIS IOR:i

PER-CENT OP CATEGORY USE

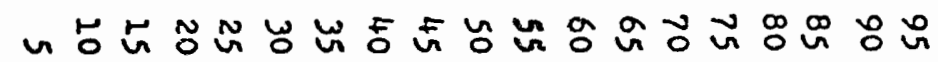

1-irodicieg

Lesson

2-Instructs \&

Demonstrates

3-Stimulates

4-Reinforces

Correct

Response

5-Punishes

Incorrect

Response

6-Reinforces

Incorrect

Response

7-Irrelevantclinician

8-Authority
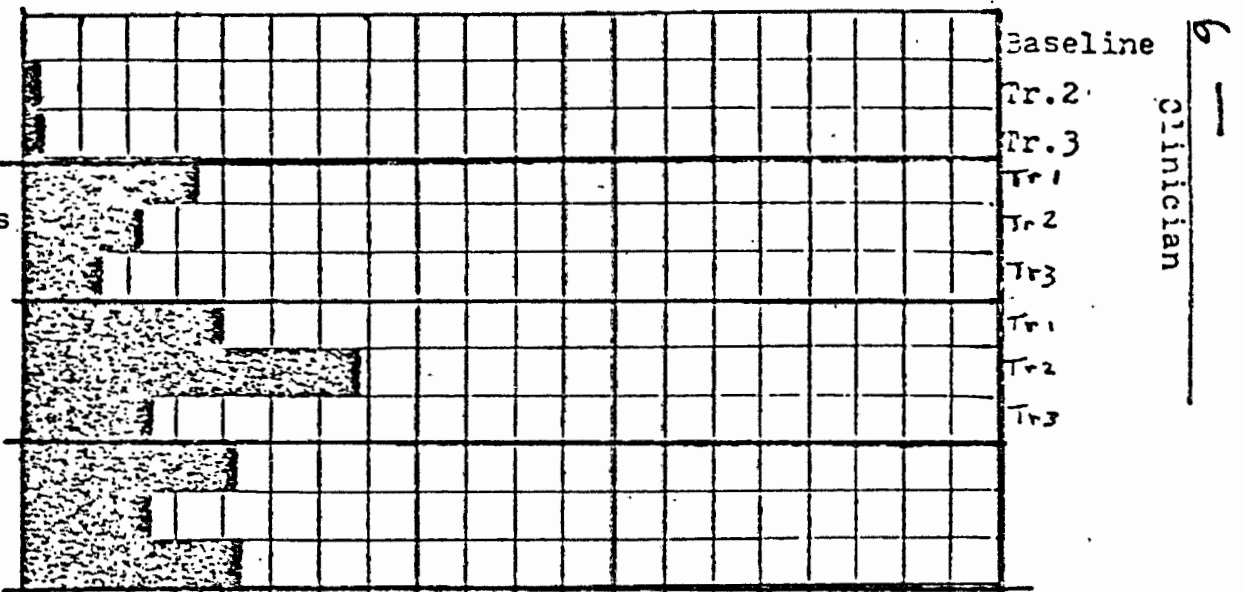

望

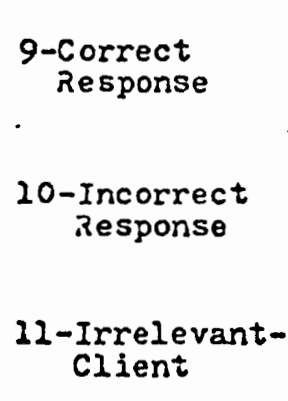

22-5ilence

a

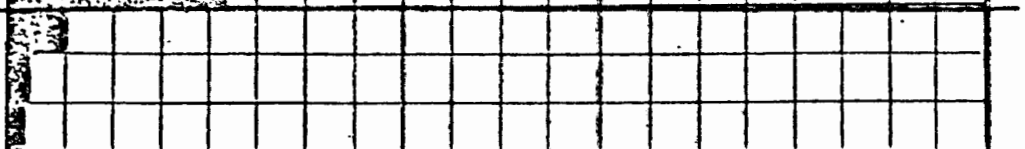

F

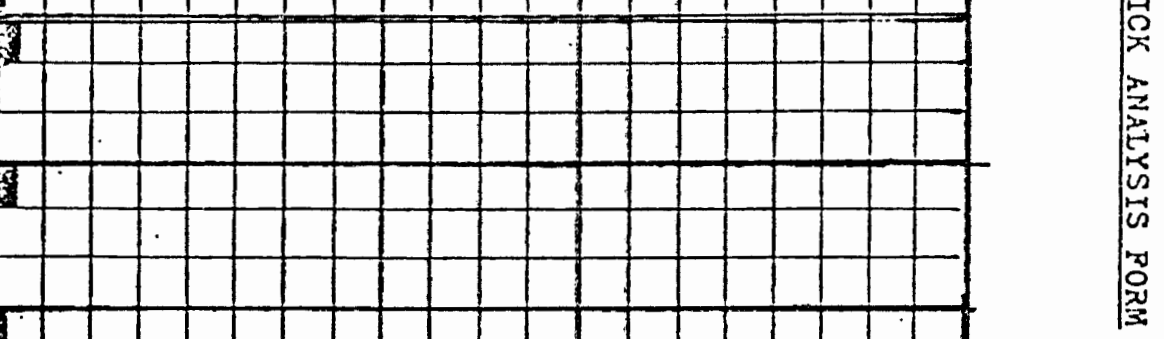




\section{APPENDIX C}

EXCERPT FROM TRAINING MANUAL FOR AN INTERACTION

ANALYSIS SYSTEM FOR IDENTIFYING THE

BEHAVIOR OF SPEECH AND LANGUAGE

CIINICIANS (MINER, 1971)

Category 1: Clinician observes the client and modifies lesson appropriately.

The ability to plan a therapy session has long been considered a desirable skill on the part of young clinicians, but a skill placed somewhat higher on the heirarchy of clinical abilities is that identified as category one. It indicates that the clinician has been able to modify the planned reaction, change a goal, or alter a strategy in terms of the response the client makes to his stimulus. For example, the clinician may ask a child to produce a target phoneme in a nonsense syliable, but in response to the request, the client says a word with the target phoneme uttered correctly. The clinician may immediately change the request from one of repeating a nonsense syllable to one of correctly producing the target phoneme in this word and other words. Another example occurs when a clinician gives a model "carrying phrase" and asks the child to use it, but the client changes the "carrying phrase" to one which is easier for him, and the clinician utilizes the child's phrase rather than insisting on the one used as a model. The modification of a demand, and the alteration 
of the therapy session occurs when the response is better than the clinician expected, or is not as good, or is different, and suggests another approach to the goal. It is easiest to recognize a Category one behavior when the lesson plans are available or the goal is known, but this is not always essential. This category is an unplanned response of the clinician to the client's behavior.

Category 2: Clinician instructs and/or demonstrates.

The process of giving directions, explaining a procedure, showing precisely how a speech or communication activity is to be conducted, or describing a motor act are all important aspects of the therapy session. There are many approaches used by clinicians to get the client to perform the desired speech or language behavior. Games. toys, books, role playing, sentence building, discussions, utilization of mechanical devices such as the tape recorders or language masters, or demonstrations in front of a mirror may be important therapy strategies. The clinician's behavior in giving directions, offering explanations, or demonstrating how to perform an act required of the client all come under this category. The explanation of a game, the instruction to "come to' the mirror with your chair and I will show you how to place your lips for the /s/ sound" are common examples. The extent to which category two is used will depend, to a large extent, on the clinician's ability to simplify directions, and to give 
pertinent, meaningful demonstrations.

Category 3, The Clinician provides auditory and/or visual stimulation

This clinical procedure is thought to be a more specific one than that just described. Category three indicates that the clinician has presented the exact word or sound or sentence to the client who is expected to repeat it as Clinician;. "Say what I say, 'Soon'; Client, "Soon." The stimulation may be a visual one in which the clinician shows a picture or presents reading matter and expects the client to say the word without any auditory clue. A frequently used visual stimuli is the number cue" used to show how many times the client is to repeat the correct phoneme, word, or sentence without interruption from the clinicians. The observer will note that the stimuli may be auditory, visual, or a combination of the two, but the intent is that the client's response will be forthcoming with little or no delay.

Category 4: The clinician provides audio and/or visual positive reinforcement of the client's correct response

If a client responds correctly the clinician often provides some type of positive reinforcer to encourage a repetition of the correct response either as the next response, or at some future time. Reinforcers take a variety of forms such as the verbal, "That's right"; 
"Good talking!": "Good! Say it againl";, or the nonverbal gesture indicating "Repeat what you just did", the smile or nod of approval, use of a counting device, or a primary reinforcer such as food. Occasionally the reinforcer is a social one in which the clinician listens to the client and carries out a command or request, or carries on a conversation, or does not interrupt as long as the speech or language response is satisfactory. The positive reinforcer may be used on a regular reinforcement schedule if such a schedule is a planned part of the therapy program, or it may be used at irregular intervals depending on the needs of the client and the philosophy of the clinician. As used in category four, the positive reinforcer always follows a correct response of the client.

Category 5, The clinician provides an audio and/or visual negative reinforcement of the client's incorrect response.

When the client responds incorrectly the clinician has several choices of behavior one of which is to indicate in some way that the response was not correct. This may be in the form of words such as, "No, that's not right"; "Try again"; "That's your old sound"; "Did that sound right?", or it may be a frown, a shake of the head, a gesture with thumbs down, or any signal known to mean the response was not correct. Negative reinforcement is much less common than positive reinforcement, however it may be necessary to provide both negative and positive reinforcers 
to help the client perceive the difference between his correct and incorrect response pattern. A category five behavior (negative reinforcer) however positively and kindly worded, has the sole intent of letting the client know that $h$ is attempt was incorrect.

Category 6, The clinician provides audio and/or visual positive reinforcement of the client's incorrect response.

As has been indicated earlier, an incorrect response offers the clinician a choice of several behaviors one of which is to provide a positive reinforcer. This behavior normally occurs when the clinician is, in some way, unaware that the response was incorrect, or when he is so desirous of having the client continue his efforts that he reinforces with an indication that the response was correct even though it was not. The verbal and non-verbal reinforcers are the same as those described under category four, but, in this instance, follow an incorrect attempt on the part of the client to perform as directed by the clinician. The most common examples are those which take place in articulation therapy when a client does not adequately produce a target phoneme, but the clinician rewards any attempt as though it were the desired one. As used in category six, the positive reinforcer always follows an incorrect response. 
Category 7, Clinician relates useless information and/or

\section{asks irrelevant questions.}

This category indicates that the clinician's behavior is not directed toward securing a response from the client nor, in any way rewarding his attempts to respond. Earlier recording with this category indicated that clinicians may spend considerable time during the therapy session carrying on a conversation with the client or relating some kind of information which is not goal directed. In most instances, this type of behavior seems to have little or no usefulness, but it is occasionally used in an effort to "establish rapport", "gain insight into the client's problems", or for some other stated purpose. When the purpose is one of establishing or maintaining a friendly client-clinician relationship, or of providing a momentary period of much needed relaxation the observer is usually quickly aware of the purpose and may, indeed score such behavior as a category one. However, when a continuous period of unnecessary conversation between the clinician and client or an extended period of "chattering" by the clinician takes place the behavior is obviously contributing little or nothing to the therapy session and should be regarded as a category. seven. 
Category 83 The clinician uses authority and/or demonstrates disapproval of client's behavior.

This category is usually used in relationship to the client's social behavior and is more frequently observed in the therapy situation with younger children than with adults. It usually occurs when the clinician is aware that the client is attempting to avoid the therapy task whether or not it is a difficult one for him to perform. The category is not meant to suggest that this is negative behavior on the part of the clinician; it merely implies that the clinician recognizes the client's evasive or avoidance behavior and is attempting to deal with it in a direct way. Common examples are noted when the clinician says such things as: "Let's get busy and see how quickly we can complete this." "Sit up in your chair and show me how hard you can work for five minutes." "John, we do not bother other people in this school"; "We can't wait for you any longer; now it is 's turn". The behavior may be non-verbal when the clinician frowns, shakes his head, points to a specific chair, crayon, or indicates a task previously requested of the child. The change in vocal tone, rate of speaking, or in carefully controlled wording is sometimes an indication that the clinician is using authority as a means of control, and may reflect knowledge that the particular client responds best to this pattern, or may be a reflection of the clinician's 
tolerance level. Regardless of the cause or of the positive or negative effect of the authoritative behavior, all such actions on the part of the clinician are recorded as category eight.

Category 9: Client responds correctly and meets the expected level of response pattern.

Category 10, Client responds incorrectly although he apparently tries to meet the demands of the clinician, he does not do so.

Categories nine and ten must be judged in terms of what the clinician asked the client to do, and whether or not his response was appropriate in terms of the clinician's directions, request, command, auditory or visual stimulus. For example if the clinician asked the client to produce a satisfactory $/ r /$ and $h$ is response is $/ w /$ it is incorrect. But, if the clinician says: "Make this sound the best you can" (shows letter $r$ ), and the client says $/ w /$, he is giving a correct response to the instructions. If the clinician asks the child to repeat a given word correctly three times and he inadvertently repeats it correctly four times, his response is correct, but if he can only repeat it once without an additional auditory model his response is not correct. If the response satisfies the clinician's criteria for success as identified 
In the goals, it is recorded as category nine; if it does not meet this criteria then it is identified as a ten even though the client is actively attempting to perform the task requested by the clinician. Categories nine and ten are determined by the antecedent behavior of the clinician as well as by the observed behavior of the client.

Category 11: Client relates useless information and/or asks irrelevant questions.

This is the type of behavior which is obviously an attempt on the part of the client to avoid following the clinician's instructions because he cannot follow them, because he does not wish to do so, or because he is engaging in "testing" behavior. The most commonly observed types are the client's direct response to the clinician's request with verbal behavior he knows is inappropriate; his attempts to begin a conversation about something irrelevant; or his request for some personal desire to be satisfied as a drink of water, the window open, a different chair, etc. Some common examples are the client's "What time is it?". "When will this lesson be over?", "What are you going to do tonight after you get through working here?", "If I don't do that will you tell my mother?", "What do you think I saw Big Bird doing on Sesame Street today?". Boone describes a category such as this as a "wastebasket" for client behavior which is not 
directly concerned with the goals of the session. The observer should be cautioned against making a value judgement regarding the appropriateness of the occasional social conversation between clinician and client, and record as a category eleven all client behaviors that are not related to the tasks identified by the clinician.

Category 12: Silence - absence of verbal and relevant motor behavior on the part of both the clinician and the client.

Frequent periods of silence may be observed during the therapy session, and they may happen for a variety of reasons. Sometimes there is a need for a brief respite when both clinician and client simply relax in a moment of quiet. On other occasions the silence is a punishing behavior, or it may reflect an unwillingness on the part of the client to follow the clinician's requests. If the client is severely handicapped, the silence may reflect the time necessary for him to make either a verbal or a motor response. On the other hand, the silence may be a "wait" period the clinician has introduced into the therapy before the response is to be attempted, or it may simply represent a skilled clinician's recognition that the client needs a brief period of time before any demand is made of him. The category twelve may be as important as 
is the pause in conversation or public speaking or it may be totally irrelevant. In either instance, silence is easy to identify and is recorded. 